BMC

Genomics

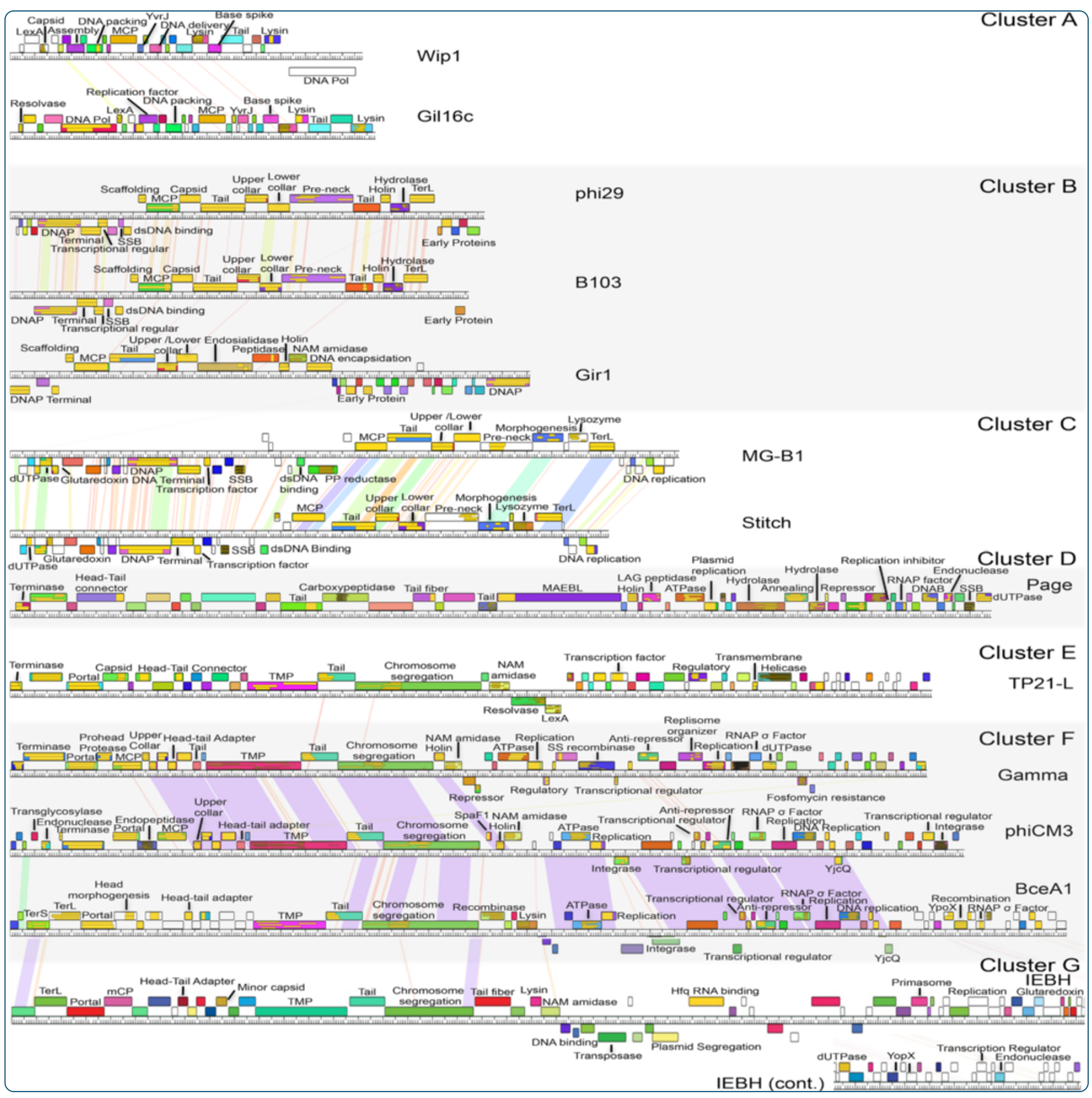

\title{
Genomic comparison of 93 Bacillus phages reveals 12 clusters, 14 singletons and remarkable diversity
}

Grose et al. 


\title{
Genomic comparison of 93 Bacillus phages reveals 12 clusters, 14 singletons and remarkable diversity
}

\author{
Julianne H Grose*, Garrett L Jensen, Sandra H Burnett and Donald P Breakwell
}

\begin{abstract}
Background: The Bacillus genus of Firmicutes bacteria is ubiquitous in nature and includes one of the best characterized model organisms, B. subtilis, as well as medically significant human pathogens, the most notorious being $B$. anthracis and $B$. cereus. As the most abundant living entities on the planet, bacteriophages are known to heavily influence the ecology and evolution of their hosts, including providing virulence factors. Thus, the identification and analysis of Bacillus phages is critical to understanding the evolution of Bacillus species, including pathogenic strains.
\end{abstract}

Results: Whole genome nucleotide and proteome comparison of the 93 extant Bacillus phages revealed 12 distinct clusters, 28 subclusters and 14 singleton phages. Host analysis of these clusters supports host boundaries at the subcluster level and suggests phages as vectors for genetic transfer within the Bacillus cereus group, with $B$. anthracis as a distant member of the group. Analysis of the proteins conserved among these phages reveals enormous diversity and the uncharacterized nature of these phages, with a total of 4,922 protein families (phams) of which only 951 (19\%) had a predicted function. In addition, 3,058 (62\%) of phams were orphams (phams containing a gene product from a single phage). The most populated phams were those encoding proteins involved in DNA metabolism, virion structure and assembly, cell lysis, or host function. These included several genes that may contribute to the pathogenicity of Bacillus strains.

Conclusions: This analysis provides a basis for understanding and characterizing Bacillus phages and other related phages as well as their contributions to the evolution and pathogenicity of Bacillus cereus group bacteria. The presence of sparsely populated clusters, the high ratio of singletons to clusters, and the large number of uncharacterized, conserved proteins confirms the need for more Bacillus phage isolation in order to understand the full extent of their diversity as well as their impact on host evolution.

Keywords: Bacteriophage, Phage, Cluster, Bacillus

\section{Background}

Bacteriophages are the most abundant biological entities on the planet, with at least $10^{31}$ bacteriophages in Earth's biosphere [1-5]. Their ability to infect and kill their bacterial hosts makes them key factors in both the evolution of bacteria and the maintenance of ecological balance (for recent reviews see [6-12]). In addition, they are able to infect and transfer genetic information to their hosts, in many cases being key factors in the transfer of

\footnotetext{
* Correspondence: julianne_grose@byu.edu

Microbiology and Molecular Biology Department, Brigham Young University, Provo, UT, USA
}

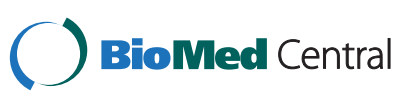

(c) 2014 Grose et al.; licensee BioMed Central Ltd. This is an Open Access article distributed under the terms of the Creative Commons Attribution License (http://creativecommons.org/licenses/by/4.0), which permits unrestricted use, distribution, and reproduction in any medium, provided the original work is properly credited. The Creative Commons Public Domain Dedication waiver (http://creativecommons.org/publicdomain/zero/1.0/) applies to the data made available in this article unless otherwise stated. pathogenic traits such as in pathogenic Escherichia coli, Salmonella sp., Corynebacterium diphtheriae and Vibrio cholerae. Despite their clear importance to global environmental and health concerns, little is known about the complexity and diversity of these living entities, but what is known from metagenomics and phage genome sequencing suggests it is vast.

The most studied bacteriophages are those that infect the Gram-positive bacterium Mycobacterium smegmatis $\mathrm{mc}^{2} 155$, with over 4,800 phages isolated and 690 fully sequenced genomes (www.phagesdb.org). These phages have been isolated by students from throughout the world as part of the Howard Hughes Medical Institute 
Science Education Alliance Phage Hunters Advancing Genomics and Evolutionary Science (HHMI SEA-PHA GES) for determining the diversity of phages that can infect a single host. A recent analysis of 491 of these indicates they belong to approximately 17 "clusters" of related phages (A-Q) and 13 singleton clusters [13]. Of interest, identical mycobacteriophages have only been isolated independently twice (Graham Hatfull, personal communication). Beyond these Mycobacterium phages, the bacterial family with the most phages isolated infect the Gramnegative Enterobacteriaceae family (337 fully sequenced genomes available in GenBank). This group of phages has been isolated and sequenced independently from investigators throughout the world and contains many of the well-characterized, historical phages such as Lambda, Mu, $\mathrm{T} 4$ and T7. They have recently been grouped into 38 clusters of phages and 18 singleton clusters [14].

A third group of well-studied phages, the Bacillus phages, have also been isolated by diverse investigators from throughout the world and infect many strains of the genus Bacillus. The Bacillus genus is ubiquitous in nature and includes one of the best characterized model organisms, B. subtilis, as well as medically significant human pathogens, the most notorious being $B$. anthracis (the causative agent of anthrax) and $B$. cereus (which causes food poisoning). Phages have been isolated that infect $B$. anthracis, B. cereus, B. megaterium, B. mycoides, B. pseudomycoides, B. subtilis, B. thuringiensis, and B. weihenstephanensis, allowing a unique opportunity to investigate the diversity of phages that infect different hosts within a bacterial genus. This study focuses on the genomic comparison of 93 fully sequenced phages that infect the Bacillus genus and discusses their place in the diversity and evolution of these important bacteria. In addition, we identify several genes that may contribute to the pathogenicity of Bacillus species. This analysis presents a framework for understanding phages that infect Bacillus and for comparing Bacillus phage diversity with the diversity of phages that infect other genera. In addition, it increases our understanding of the evolution and diversity of phages and their hosts, including the evolution of pathogenic strains.

\section{Results and discussion}

Whole genome nucleotide and amino acid comparison of the Bacillus family of phages reveals 12 diverse clusters and 14 singletons

In order to determine the relationship of the 93 extant, fully-sequenced Bacillus phages as of June 1, we analyzed the published phage genomes by methods similar to those of Hatfull et al. [15,16], including whole genome dot plot analysis, pairwise average nucleotide identities (ANI) and genomic maps. The accession numbers and basic properties (host, genome size, GC content, number of ORFs, number of tRNAs and morphotype) of the 93 full sequenced Bacillus phages are provided in Table 1 along with the appropriate reference.

Dot plot analysis of the Bacillus phages revealed 12 clusters of phages with similarity over at least $50 \%$ of their genomes (clusters A through L) and 14 phages that are singletons, having little to no nucleotide similarity to any other Bacillus phages. Genomic dot plot analysis consists of placing the nucleotide sequences across both the $\mathrm{X}$ - and Y-axis. A dot is placed where the sequences are identical resulting in a diagonal line down the center of the plot when a sequence is compared to itself. The phages were aligned on two separate plots due to the wide range in genome size and the fact that no additional nucleotide similarity was seen in a combined plot. Figure $1 \mathrm{~A}$ contains phage genomes less than $100 \mathrm{~kb}$ while $1 \mathrm{C}$ contains the larger phage genomes. As stated above, assignment of a phage to a cluster was based on nucleotide similarity over at least $50 \%$ of the genome when compared to at least one other phage in the cluster. Thus, a phage could be placed into the same cluster by weak similarity over most of the genome, by strong similarity over about half of the genome, or by a combination of relatedness. The ANI values were also calculated within each cluster and found to be at least 55\% between a phage and another phage within a cluster. From the total of 26 clusters just over half (14) are singleton clusters containing a single phage member, suggesting that the isolation of unique Bacillus phages is far from complete.

In addition to showing strong evolutionary relationships, whole genome nucleotide dot plots also reveal smaller regions of homology ( $<50 \%$ span length) between phages of different clusters that are likely areas of recombination. The largest such region is a $\sim 10,000$ bp region of similarity between phBC6A51 (bp 44289-50616 and 58088-61389) and cluster $\mathrm{F}$ phages that includes a tail component protein, minor structural protein and holin as well as a sitespecific recombinase, a Ftsk/SpoIIIE family protein and five conserved phage proteins.

In addition to whole genome nucleotide analysis, whole proteome dot plot analysis was performed (Figures $1 \mathrm{~B}$ and D). Because nucleotide sequences diverge more rapidly, the amino acid dot plots were expected to reveal more distant evolutionary relationships. The analysis confirmed the basic cluster assignments seen with whole genome nucleotide analysis and revealed distant relationships between the E, F, G and I clusters discussed in more detail below. Note that there should be some limited similarity between all of the Bacillus tailed phages in that they should all encode a major capsid protein (MCP), portal protein and terminase. However, these proteins can diverge to a point that no sequence similarity is apparent.

Another common way to group phages is by the percent of the proteome that is conserved between phages. 
Table 1 Characteristics of reported Bacillus phages with complete genome sequences

\begin{tabular}{|c|c|c|c|c|c|c|c|c|c|}
\hline Cluster & Phage name & Host & Size (bp) & GC\% & ORFS & tRNA & Accession Number & Family & Ref. \\
\hline A1 & Wip1 & $A$ & 14319 & 36.84 & 27 & 0 & NC_022094 & $T$ & $\overline{[17]}$ \\
\hline A1 & AP50 & A & 14398 & 38.65 & 31 & 0 & NC_011523 & $T$ & [18] \\
\hline$A 2$ & GIL16C & T & 14844 & 39.72 & 32 & 0 & NC_006945 & $T$ & [19] \\
\hline$A 2$ & Bam35c & T & 14935 & 40.08 & 31 & 0 & AY257527 & $T$ & [19] \\
\hline$A 2$ & pGIL01 & T & 14931 & 39.73 & 30 & 0 & AJ536073 & $T$ & {$[20]$} \\
\hline B1 & Phi29 & S & 19282 & 39.99 & 27 & 0 & EU771092.1 & $P$ & [21] \\
\hline B1 & PZA & $S$ & 19366 & 39.66 & 27 & 0 & M11813 & $P$ & {$[22]$} \\
\hline B2 & B103 & S & 18630 & 37.66 & 17 & 0 & NC_004165 & $P$ & [23] \\
\hline B2 & $\mathrm{Nf}$ & S & 18753 & 37.32 & 27 & 0 & EU622808 & $P$ & \\
\hline B3 & Gir1 & B & 21129 & 34.65 & 34 & $0^{*}$ & & P & $* * *$ \\
\hline B3 & GA-1 & B & 21129 & 34.66 & 35 & 1 & X96987 & $P$ & [24] \\
\hline $\mathrm{C} 1$ & MG-B1 & w & 27190 & 30.75 & 42 & 0 & NC_021336 & S & {$[25]$} \\
\hline $\mathrm{C} 2$ & Stitch & B & 24320 & 30.36 & 37 & $0^{*}$ & & $P$ & $* * *$ \\
\hline D1 & Page & M & 39874 & 40.71 & 50 & $0^{*}$ & NC_022764 & & {$[26]$} \\
\hline D1 & Poppyseed & M & 39874 & 40.71 & 50 & 0 & KF669657 & & $* * *$ \\
\hline D1 & Pony & M & 39844 & 40.70 & 48 & 0 & NC_022770 & P & [27] \\
\hline E1 & TP21-L & C & 37456 & 37.80 & 56 & 0 & NC_011645 & $S$ & [28] \\
\hline E1 & BMBtp2 & $\mathrm{T}$ & 36932 & 37.79 & 53 & 0 & NC_019912 & $S$ & $* * *$ \\
\hline E1 & ProCM3 & T & 43278 & 37.36 & 66 & $0^{*}$ & KF296717 & $S$ & $* * *$ \\
\hline $\mathrm{F} 1$ & $\gamma$ isolate d'Herelle & A & 37373 & 35.13 & 53 & 0 & DQ289556 & $S$ & {$[29]$} \\
\hline $\mathrm{F} 1$ & $\gamma$ isolate 51 & A & 37253 & 35.22 & 53 & 0 & DQ222853 & $S$ & $* * *$ \\
\hline $\mathrm{F} 1$ & WBeta & A & 40867 & 35.26 & 53 & 0 & DQ289555 & $S$ & {$[29]$} \\
\hline $\mathrm{F} 1$ & Gamma & A & 37253 & 35.22 & 53 & 0 & NC_007458 & $S$ & {$[30]$} \\
\hline $\mathrm{F} 1$ & Cherry & A & 36615 & 35.27 & 51 & 0 & DQ222851 & $S$ & 27) \\
\hline $\mathrm{F} 1$ & $\gamma$ isolate 53 & A & 38067 & 35.10 & 50 & 0 & DQ222855 & $S$ & \\
\hline $\mathrm{F} 1$ & Fah & B & 37974 & 34.95 & 50 & 0 & NC_007814 & $S$ & [31] \\
\hline $\mathrm{F} 2$ & phicM3 & T & 38772 & 35.48 & 56 & $0^{*}$ & NC_023599 & & $* * *$ \\
\hline F2 & phIS3501 & T & 44401 & 34.86 & 51 & 1 & JQ062992 & $S$ & $* * *$ \\
\hline F2 & BtCS33 & T & 41992 & 35.22 & 57 & 0 & NC_018085 & $S$ & [32] \\
\hline F3 & BceA1 & C & 42932 & 35.66 & 63 & 0 & HE614282 & & [33] \\
\hline G1 & IEBH & T & 53104 & 36.42 & 86 & 0 & EU874396 & $S$ & \\
\hline G1 & 250 & C & 56505 & 36.44 & 54 & 0 & GU229986 & & [34] \\
\hline $\mathrm{H} 1$ & Andromeda & P & 49259 & 41.91 & 79 & 0 & NC_020478 & $S$ & \\
\hline $\mathrm{H} 1$ & Gemini & P & 49362 & 41.9 & 79 & 0 & KC330681 & $S$ & \\
\hline $\mathrm{H} 1$ & Glittering & P & 49246 & 42.05 & 78 & 0 & NC_022766 & $S$ & [35] \\
\hline $\mathrm{H} 1$ & Curly & P & 49425 & 41.82 & 77 & 0 & NC_020479 & $S$ & \\
\hline $\mathrm{H} 1$ & Eoghan & $P$ & 49458 & 42.21 & 75 & 0 & NC_020477 & $S$ & \\
\hline $\mathrm{H} 1$ & Taylor & P & 49492 & 42.29 & 75 & 0 & KC330682 & $S$ & \\
\hline $\mathrm{H} 1$ & Riggi & P & 49836 & 41.46 & 79 & 0 & NC_022765 & $S$ & [36] \\
\hline $\mathrm{H} 1$ & Blastoid & P & 50354 & 42.23 & 79 & 0 & NC_022773 & $S$ & [37] \\
\hline $\mathrm{H} 1$ & Finn & M & 50161 & 41.69 & 77 & 0 & NC_020480 & $S$ & \\
\hline $\mathrm{H} 1$ & Polaris & B & 33403 & 42.61 & 45 & $0^{*}$ & & & $* * *$ \\
\hline 11 & Pleiades & B & 64698 & 47.66 & 112 & $0^{*}$ & & & $* * *$ \\
\hline 11 & Pappano & B & 65662 & 47.57 & 113 & $0^{*}$ & & & $* * *$ \\
\hline
\end{tabular}


Table 1 Characteristics of reported Bacillus phages with complete genome sequences (Continued)

\begin{tabular}{|c|c|c|c|c|c|c|c|c|c|}
\hline $\mathrm{J1}$ & Staley & $M$ & 81656 & 35.35 & 113 & 0 & NC_022767 & $S$ & [38] \\
\hline J1 & Slash & M & 80382 & 35.23 & 111 & 0 & KF669661 & $S$ & [39] \\
\hline$J 2$ & Basilisk & C & 81790 & 33.9 & 141 & 2 & KC595511 & $S$ & {$[40]$} \\
\hline K1 & SPO1 & $\mathrm{S}$ & 132562 & 39.97 & 204 & 5 & NC_011421 & M & [41] \\
\hline $\mathrm{K} 1$ & Pegasus & B & 146685 & 40.3 & 236 & $3^{*}$ & & & [42] \\
\hline K1 & CampHawk & $S$ & 146193 & 40.2 & 231 & 2 & NC_022761 & M & [43] \\
\hline $\mathrm{K} 2$ & Shanette & $C$ & 138877 & 40.8 & 223 & 3 & KC595513 & M & {$[40]$} \\
\hline $\mathrm{K} 2$ & $J \mathrm{~L}$ & C & 137918 & 40.8 & 222 & 4 & KC595512 & M & [40] \\
\hline L1 & phiNIT1 & $P$ & 155631 & 42.12 & 219 & 4 & NC_021856 & & \\
\hline L1 & Grass & $S$ & 156648 & 42.25 & 252 & 3 & NC_022771 & & [44] \\
\hline L2 & SIOphi** & S & 146698 & 39.02 & 206 & $0^{*}$ & KC699836 & M & \\
\hline L3 & phiAGATE & $P$ & 149844 & 49.97 & 210 & 4 & NC_020081 & & [45] \\
\hline L4 & Bastille & C & 153962 & 38.14 & 280 & 7 & JF966203 & M & {$[45]$} \\
\hline L4 & Evoli & $\mathrm{T}$ & 159656 & 38.06 & 293 & 8 & KJ489398 & & \\
\hline$\llcorner 4$ & HoodyT & $T$ & 159837 & 38.01 & 299 & 8 & KJ489400 & M & \\
\hline L4 & CAM003 & $\mathrm{T}$ & 160541 & 38.03 & 296 & 8 & KJ489397 & & \\
\hline L4 & JPB9 & B & 159478 & 38.00 & 322 & $5^{*}$ & & & $* * *$ \\
\hline L5 & B4 & C & 162596 & 37.71 & 277 & 0 & JN790865 & & \\
\hline L5 & Troll & $T$ & 163019 & 37.83 & 289 & 0 & NC_022088 & M & \\
\hline L5 & Spock & $\mathrm{T}$ & 164297 & 37.62 & 283 & 0 & NC_022763 & M & \\
\hline L5 & Adelynn & B & 165049 & 37.77 & 293 & $0^{*}$ & & & {$[46]$} \\
\hline L5 & BigBertha & $\mathrm{T}$ & 165238 & 37.77 & 291 & 0 & NC_022769 & M & [47] \\
\hline L5 & Riley & B & 162816 & 37.78 & 290 & 0 & NC_024788. & & $* * *$ \\
\hline L5 & B5S & $C$ & 162598 & 37.71 & 272 & 0 & JN797796 & M & {$[48]$} \\
\hline L6 & BCP78 & C & 156176 & 39.86 & 227 & 18 & JN797797 & M & [49] \\
\hline L6 & $\mathrm{BCU} 4$ & C & 154371 & 39.86 & 223 & 19 & JN797798 & M & {$[50]$} \\
\hline L7 & $\mathrm{BCP} 1$ & C & 152778 & 39.76 & 227 & $17^{*}$ & KJ451625 & M & \\
\hline L7 & Bc431v3 & C & 158621 & 39.98 & 238 & 21 & JX094431 & M & [51] \\
\hline L8 & Hakuna & $\mathrm{T}$ & 158100 & 38.70 & 294 & 0 & KJ489399H & & \\
\hline L8 & Doofenshmirtz & B & 161793 & 38.74 & 294 & $0^{*}$ & & & $* * *$ \\
\hline L8 & Nagalana & B & 163041 & 38.75 & 302 & $0^{*}$ & & M & $* * *$ \\
\hline L8 & Megatron & $\mathrm{T}$ & 158750 & 38.80 & 291 & 0 & KJ4894011H & & \\
\hline L8 & BPS10C & C & 159590 & 38.74 & 271 & 0 & NC_023501 & M & [52] \\
\hline L8 & BPS13 & C & 158305 & 38.75 & 268 & 0 & JN654439 & M & [52] \\
\hline L8 & W. Ph. & C & 156897 & 36.45 & 274 & 0 & HM144387 & M & [26] \\
\hline Single & BV1 & B & 35055 & 44.85 & 54 & 0 & DQ840344 & & \\
\hline Single & phBC6A52 & $C$ & 38472 & 34.72 & 49 & 0 & NC_004821 & & \\
\hline Single & phi105 & M & 39325 & 42.69 & 51 & 0 & NC_004167 & $S$ & [53] \\
\hline Single & $\mathrm{BCJA1C}$ & B & 41092 & 41.74 & 58 & 0 & NC_006557 & $S$ & \\
\hline Single & PBC1 & C & 41164 & 41.68 & 50 & 0 & JQ619704 & $S$ & [54] \\
\hline Single & SPP1 & M & 44010 & 43.72 & 99 & 0 & NC_004166 & $S$ & [55] \\
\hline Single & PM1 & S & 50861 & 41.29 & 86 & 0 & NC_020883 & $S$ & {$[56]$} \\
\hline Single & phBC6A51 & $\mathrm{T}$ & 61395 & 37.69 & 75 & 0 & NC_004820 & & [57] \\
\hline Single & BCD7 & C & 93839 & 38.04 & 140 & 0 & JN712910 & & \\
\hline Single & SPBC2 & $S$ & 134416 & 34.64 & 185 & 0 & NC_001884 & $S$ & [58] \\
\hline
\end{tabular}


Table 1 Characteristics of reported Bacillus phages with complete genome sequences (Continued)

\begin{tabular}{lccccccccc}
\hline Single & SP10 & S & 143986 & 40.49 & 236 & 0 & NC_019487 & $M$ & [40] \\
Single & BanS-Tsamsa & A & 168876 & 34.32 & 272 & 19 & NC_023007 & S & [59] \\
Single & 0305phi8-36 & T & 218948 & 41.8 & 246 & 0 & NC_009760 & $M$ \\
Single & G & M & 497513 & 29.93 & 675 & $18^{*}$ & JN638751 & [59] \\
\hline
\end{tabular}

Hosts are the bacterial hosts on which the phages were isolated (not the host range) and are abbreviated as Bacillus anthracis (A), Bacillus cereus (C), Bacillus sp. (B), Bacillus megaterium (M), Bacillus pumulis (P), Bacillus subtilis (S), Bacillus thuringiensis (T), and Bacillus weihenstephanensis (W). ORFs are the number of Open Reading Frames predicted to be encoded by the genome as provided in the reported annotation. Family is Myoviridae (M), Siphoviridae (S) or Podoviridae (P). A reference (Ref.) for the published genome is provided when available.

*tRNA predicted in this study using Aragorn and DNAMaster.

**Phage SIOphi is reported as an incomplete genome but is included in this analysis because it was complete enough to clearly assign it to a cluster.

***Indicates phage sequences obtained through phagesdb.org.

CoreGenes 3.0 was used to confirm clusters by ensuring that phages within a cluster share $\sim 40 \%$ of their proteome, a cutoff commonly used for determining phage relationships $[63,64]$. The cluster with the lowest conservation of the proteome (that is, the lowest conservation between a phage and its closest relative) is the F cluster, with the highly related phages Staley and Slash sharing only $43.4 \%$ of their proteome with Basilisk. All other clusters yielded proteome comparison scores well above the $40 \%$ CoreGenes threshold, confirming that the phages belong in the proposed clusters.

The division of phages into the proposed clusters is also supported by the low standard deviation in the average basic phage properties including genome size, GC content, number of ORFs and morphotype (Table 2). For example, cluster A consists completely of tectiviruses of an average genome size of $14685 \pm 302 \mathrm{bp}$, clusters B and $\mathrm{D}$ of podoviruses with short tails (average genome size is $19715 \pm 1132$ and $39864 \pm 17 \mathrm{bp}$, respectively), clusters C, E, F, G, H and J of long noncontractile siphoviruses (average genome size ranging from $25755 \pm 2029$ to $81276 \pm 777 \mathrm{bp})$, and the large contractile myovirus clusters $\mathrm{K}$ and L (average genome size is $140447 \pm 5978$ and $158753 \pm 4550 \mathrm{bp}$, respectively). Cluster I is of unknown morphotype. The average number of tRNA's for each cluster is also reported but is highly variable within a cluster with standard deviations often approaching the number of tRNA's. This variation may reflect the phages' adaptation to different hosts since tRNA's are thought to provide efficient protein production in hosts with alternate codon preferences [65]. Further host range studies are needed to test these hypotheses.

\section{Division of clusters into subclusters reveals large variance between clusters}

Each cluster was further analyzed by nucleotide dot plot to reveal groups of high similarity, or subclusters (Figures 2 and 3). These subclusters were chosen based on natural divisions in phage similarity seen in the dot plot, but could be more strictly defined by ANI values of at least $66 \%$ between two phages within the subcluster. The subcluster assignments indicate great diversity in the relatedness within each Bacillus phage cluster. It is unknown whether this diversity represents evolutionary forces that constrain certain types of phages or if it is an artifact of phage isolation. Further phage isolation is necessary for this distinction.

\section{Clusters containing highly related phages}

Clusters C, D, E, H, and I are each comprised of a single subcluster containing highly related phages (sharing at least $74 \% \mathrm{ANI}$ ). Cluster $\mathrm{H}$ is the largest cluster and contains 10 highly related siphovirus phages, the cluster D and cluster $\mathrm{E}$ each contain three phages of the podovirus and siphovirus families, respectively, cluster $\mathrm{C}$ contains two siphoviruses, and cluster I contains two phages of unknown morphotype. The majority of phages in each of these clusters are recently isolated phages that are not well-characterized. In fact, the MCP was not annotated for any cluster D, E, H or I phage and we were unable to identify an MCP by TBLASTN searches, suggesting that the MCP of these phages are novel.

\section{Clusters containing more distantly related phages}

Clusters A, B, F, G, J, K and L all contain multiple subclusters, with B, F, J and $\mathrm{K}$ being the most variable. Cluster $\mathrm{B}$ contains three subclusters having ANI values ranging from $48 \%$ to $76 \%$ between phages (but all phages have at least $54 \%$ with at least one other phage in a different subcluster). A CoreGenes 3.0 analysis confirms this relationship of cluster B phages, with B1 phages sharing 96\% of their proteome within the subcluster but approximately $63 \%$ and 56\% with the B2 and B3 cluster proteomes, respectively. Similarly, cluster F contains 11 phages divided into 3 subclusters where ANI varies from $42 \%$ to $99.99 \%$ between phages but all phages have at least $55 \%$ to one another. There is $86 \%$ proteome conservation within each subcluster, and between subclusters there is at least $41 \%$ proteome conservation. Cluster J harbors the very similar Staley and Slash (94\% ANI) and the more distantly related phage Basilisk, which shares $~ 55 \%$ ANI and $43 \%$ of its proteome with Staley/Slash. Cluster K harbors SPO1 and close relatives CampHawk and Pegasus (subcluster K1) as well as the more distantly related phages Shanette and JL 

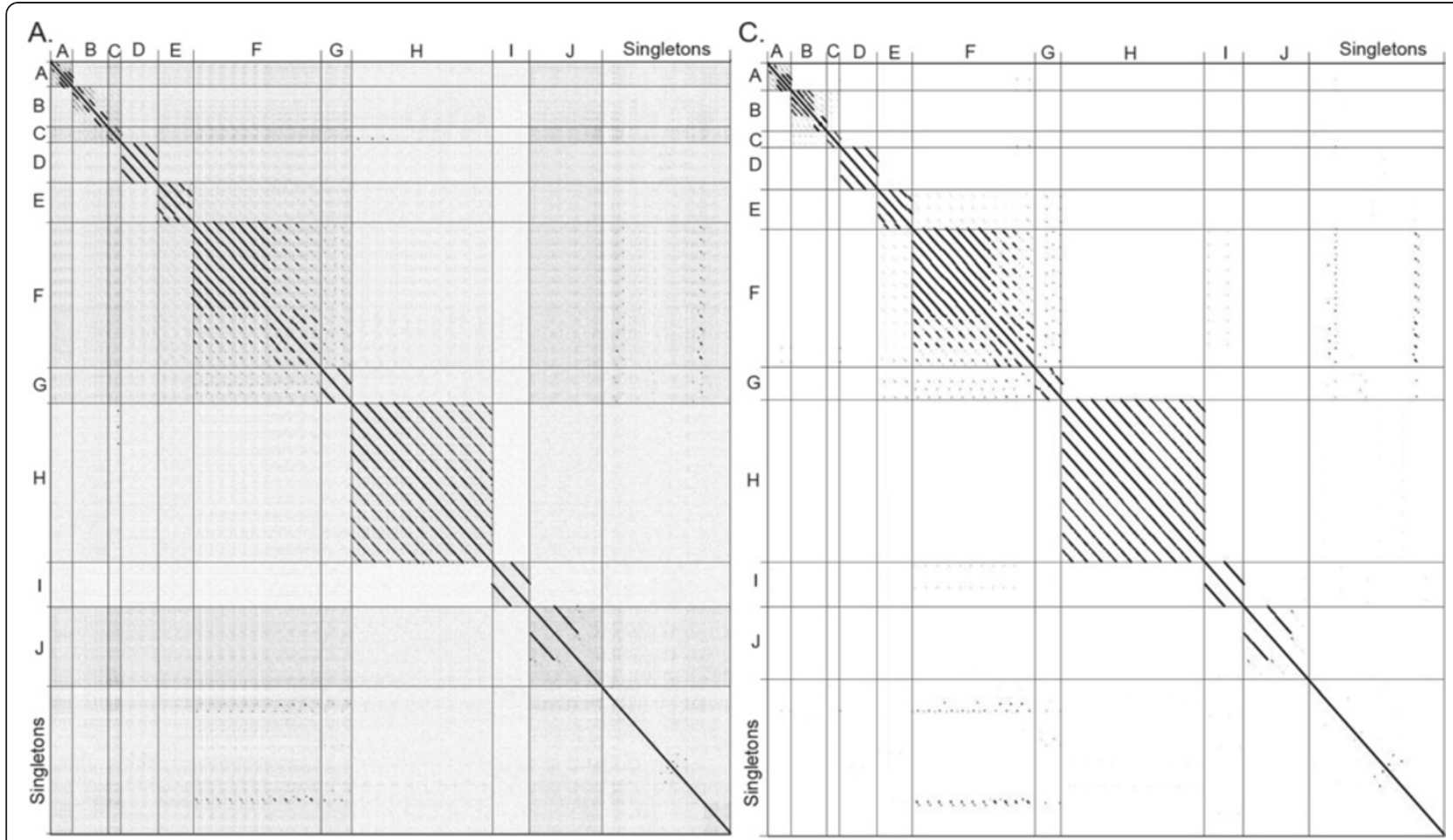

B.

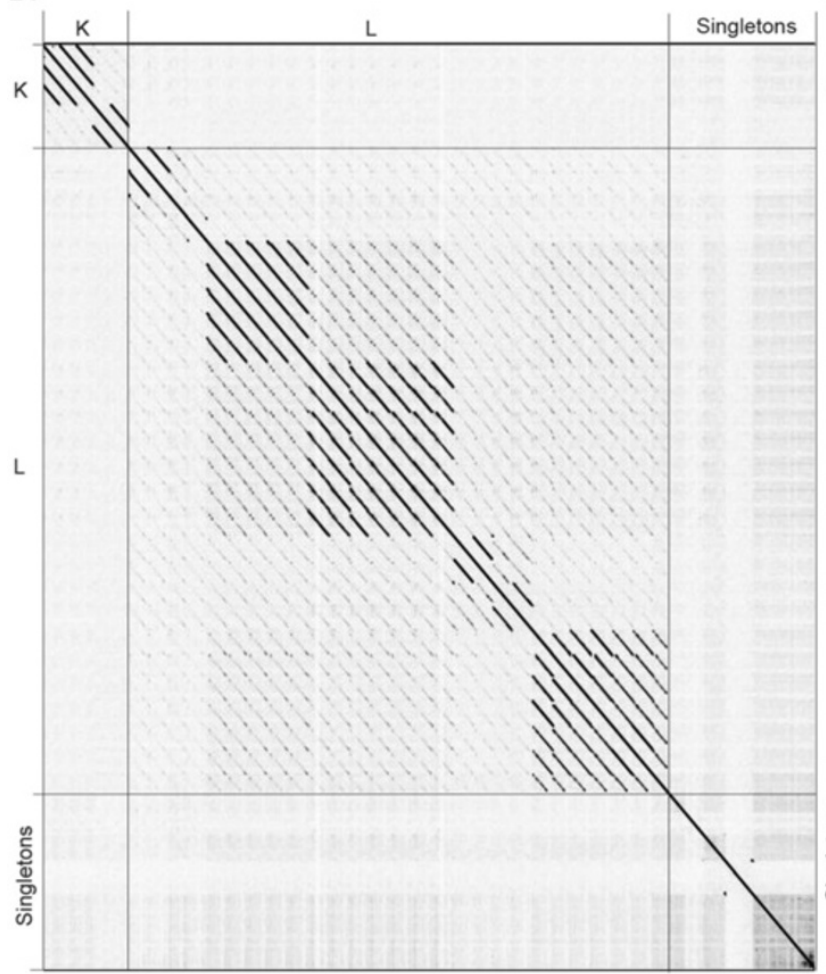

D.

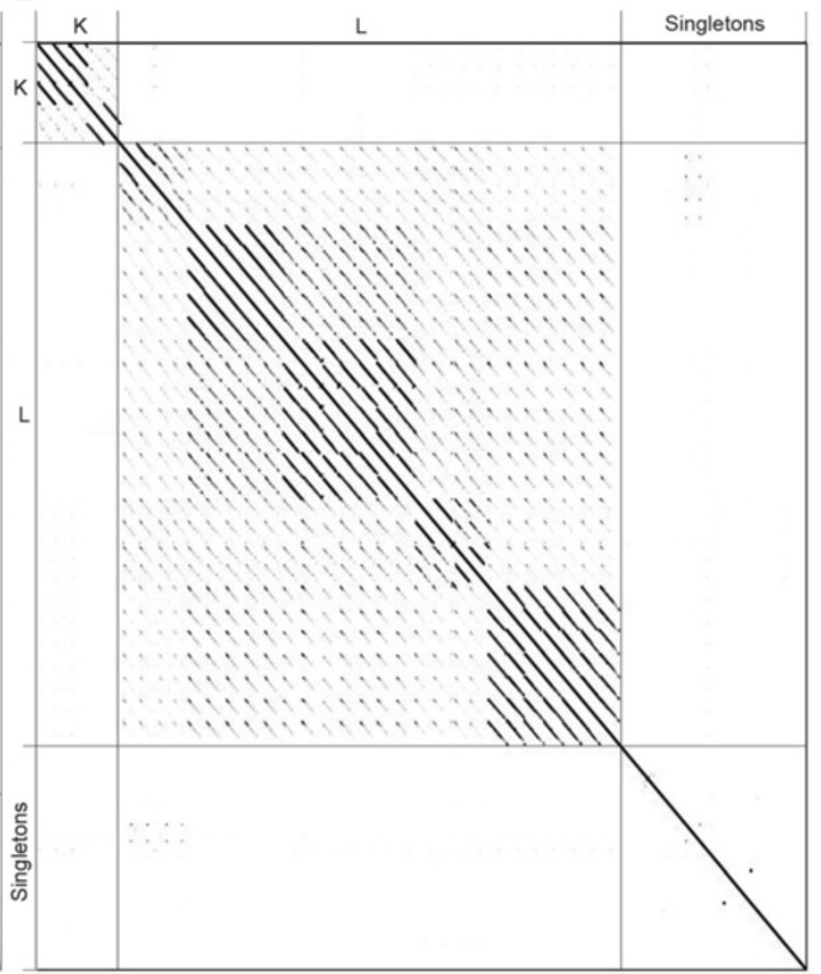

Figure 1 Nucleotide and amino acid dot plot analysis of 93 fully sequenced Bacillus phages reveals 12 clusters (A-L) and 14 singletons. Nucleotide (A) and amino acid (C) dot plot of Bacillus genomes of less than $100 \mathrm{~kb}$ organized by similarity reveals 10 clusters of related phages. Nucleotide (B) and amino acid (D) dot plot of Bacillus genomes of greater than $100 \mathrm{~kb}$ organized by similarity reveals 2 clusters of related phages. Thick lines indicate cluster assignments, which are provided on the Y-axis (A-L). Dot plots were produced using Gepard [61] and whole genome amino acid sequences were retrieved from Phamerator [62]. 
Table 2 Summary of Bacillus cluster phage characteristics

\begin{tabular}{cccccccc}
\hline Cluster & Sub. & Phages & Hosts & Genome size & \%GC & \# ORFS (tRNA) & Type \\
\hline A & 2 & 5 & A, T & $14685 \pm 302$ & $39.0 \pm 1,3$ & $30.2 \pm 1.9(0)$ & T \\
B & 3 & 6 & B, S & $19715 \pm 1132$ & $37.3 \pm 2.3$ & $27.8 \pm 6.5(0.2 \pm 0.4)$ \\
C & 2 & 2 & B, W & $25755 \pm 2029$ & $30.6 \pm 0.3$ & $39.5 \pm 3.5(0)$ & S \\
D & 1 & 3 & M & $39864 \pm 17$ & $40.7 \pm 0.0$ & $49.3 \pm 1.2(0)$ & P \\
E & 1 & 3 & C, T & $39222 \pm 3522$ & $37.7 \pm 0.3$ & $38.7 \pm 10.2(0)$ & S \\
F & 3 & 11 & A, B, C, T & $39409 \pm 2677$ & $35.2 \pm 0.2$ & $53.6 \pm 3.8(0.1 \pm 0.3)$ & S \\
G & 1 & 2 & C, T & $54805 \pm 2405$ & $36.4 \pm 0.0$ & $70.0 \pm 22.6(0)$ & S \\
H & 1 & 10 & B, M, P & $48000 \pm 5143$ & $42.0 \pm 0.3$ & $14.3 \pm 10.4(0)$ \\
I & 1 & 2 & B & $65180 \pm 682$ & $47.6 \pm 0.1$ & $12.5 \pm 0.7(0)$ & S \\
J & 2 & 3 & C, M & $81276 \pm 777$ & $34.8 \pm 0.8$ & $122 \pm 16.8(0.7 \pm 1.2)$ & S \\
K & 2 & 5 & B, C, S & $140447 \pm \pm 5978$ & $40.4 \pm 0.4$ & $223 \pm 12.2(3.4 \pm 1.1)$ & M \\
L & 8 & 27 & B, C, P, S, T & $158753 \pm 4550$ & $39.1 \pm 2.5$ & $269.7 \pm 32.2(5.0 \pm 6.7)$ & M \\
\hline
\end{tabular}

Characteristics given are cluster assignment, number of subclusters (Sub.), number of phages in the cluster, host species from which the phages were isolated, the average genome size, average percent GC content, average number of ORFS with average number tRNA in parenthesis, and the morphotype. Averages are given with the standard deviation. Species abbreviations are Bacillus anthracis (A), Bacillus cereus (C), Bacillus sp. (B), Bacillus megaterium (M), Bacillus pumulis (P), Bacillus subtilis (S), Bacillus thuringiensis (T), and Bacillus westenstephanensis MG1, (W). Family/morphotype abbreviations are Tectiviridae (T), Podoviridae (P), Siphoviridae (S), and Myoviridae (M). UK is unknown/unreported.

(subcluster K2), which share $\sim 53 \%$ of their proteomes with the $\mathrm{K} 1$ phages.

Clusters $\mathrm{G}$ and L contain more closely related phages. Cluster $\mathrm{G}$ harbors siphoviruses IEBH and 250 which share $90 \%$ ANI and $55 \%$ of their proteomes. $\mathrm{L}$ is the largest cluster and contains 27 phages that are likely to all be myoviruses since 15 are reported as such. Of interest, these seven subclusters to which these large phages belong are highly variable in host, tRNA content and number of ORF's (see Table 1), but they are all highly related having at least $81 \%$ ANI.

Overall, Bacillus phages remain highly uncharacterized but clusters $\mathrm{F}$ and $\mathrm{K}$ contain a couple of well-characte rized Bacillus phages including the $B$. anthracis typing phages Gamma and Cherry and B. subtilis phages SPO1 and CampHawk, respectively.

\section{Single gene product analysis mirrors whole genome/ proteome analysis}

In addition to using whole genome or proteome comparisons to determine phage cluster assignment we recently demonstrated the utility of single gene product analysis using the mycobacteriophage tape measure protein (TMP) and major capsid protein (MCP) gene products [66]. We were unable to use either TMP or MCP for Bacillus phage single-gene comparison because podoviruses do not have a TMP and the MCP was not reported or identified by a TBLASTN search for 18 of the 93 Bacillus phages (including clusters D, E, H and I). Three genes are thought to be common to all tailed phages, the MCP (the major constituent of the icosahedral shell), portal protein (forms the pore into the capsid through which the DNA is packaged) and large terminase (the ATPase that packages the DNA into capsid) [67]. A putative large terminase gene product (TerL) was identified in $100 \%$ of the Bacillus phages and was, therefore, used for single-gene comparison (Figure 4). A dot plot alignment of the terminase gene products (TerL) confirmed our basic cluster/subcluster assignment with 100\% of phages grouping by their pre-assigned clusters or subclusters, and 11 of 14 singletons remaining singletons. This overall percentage (96.8\%) is comparable to the $98.8 \%$ reported for the mycobacteriophages using TMP [66]. The terminase dot plot analysis is supported by a neighborjoining tree in which all of the proteins grouped by cluster/ subcluster and the same three singletons were associated with another cluster (Figure 5). The few outliers are consistent with a recent analysis that suggested genes encoding TerL have undergone sufficient horizontal transfer between phage groups to disrupt some correlations between terminase sequence type and cluster relationship [68].

From single-gene comparison, two of the subclusters appear to be unrelated to the rest of the cluster in which they belong (subcluster B3 and F3) while three singletons (SPP1, $\mathrm{PBC} 1$ and SP10) display remarkable similarity to the $\mathrm{D}, \mathrm{F} / \mathrm{G}$ or $\mathrm{K} / \mathrm{L}$ clusters, respectively, as seen by both dot plot and neighbor-joining tree analysis. These relationships could indicate more distant/ancient relationships over the entire chromosome or small regions of genetic exchange. The limited similarity of subcluster B3 and F3 TerL proteins to the rest of the $\mathrm{B}$ and $\mathrm{F}$ clusters is consistent with their distant whole genome/proteome relationships (faint diagonal lines on both the nucleotide and amino acid dot plots, see Figure 1). In contrast, CoreGenes analysis suggests small 


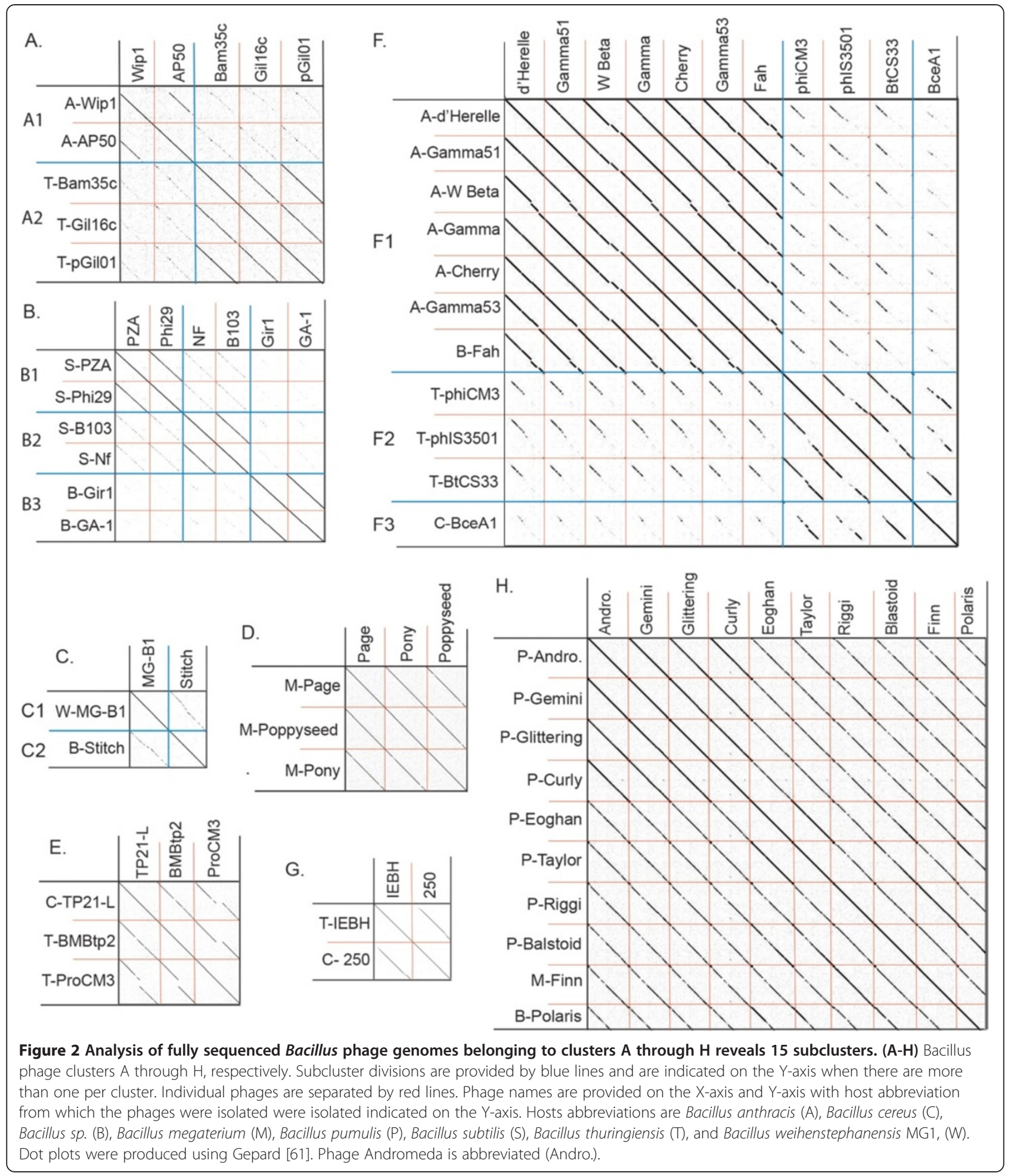

regions of genetic exchange for SSP1 in that it shares only $\sim 5 \%$ of its proteome with the cluster $\mathrm{D}$ phages (including the terminase, tailspike, $\mathrm{DnaB} / \mathrm{DnaD}$ replication protein, and the single stranded DNA binding and annealing proteins).

\section{Predicting phage replication strategies by terminase} conservation

The identification and analysis of Bacillus phage terminase proteins presented in Figure 5 can also provide 


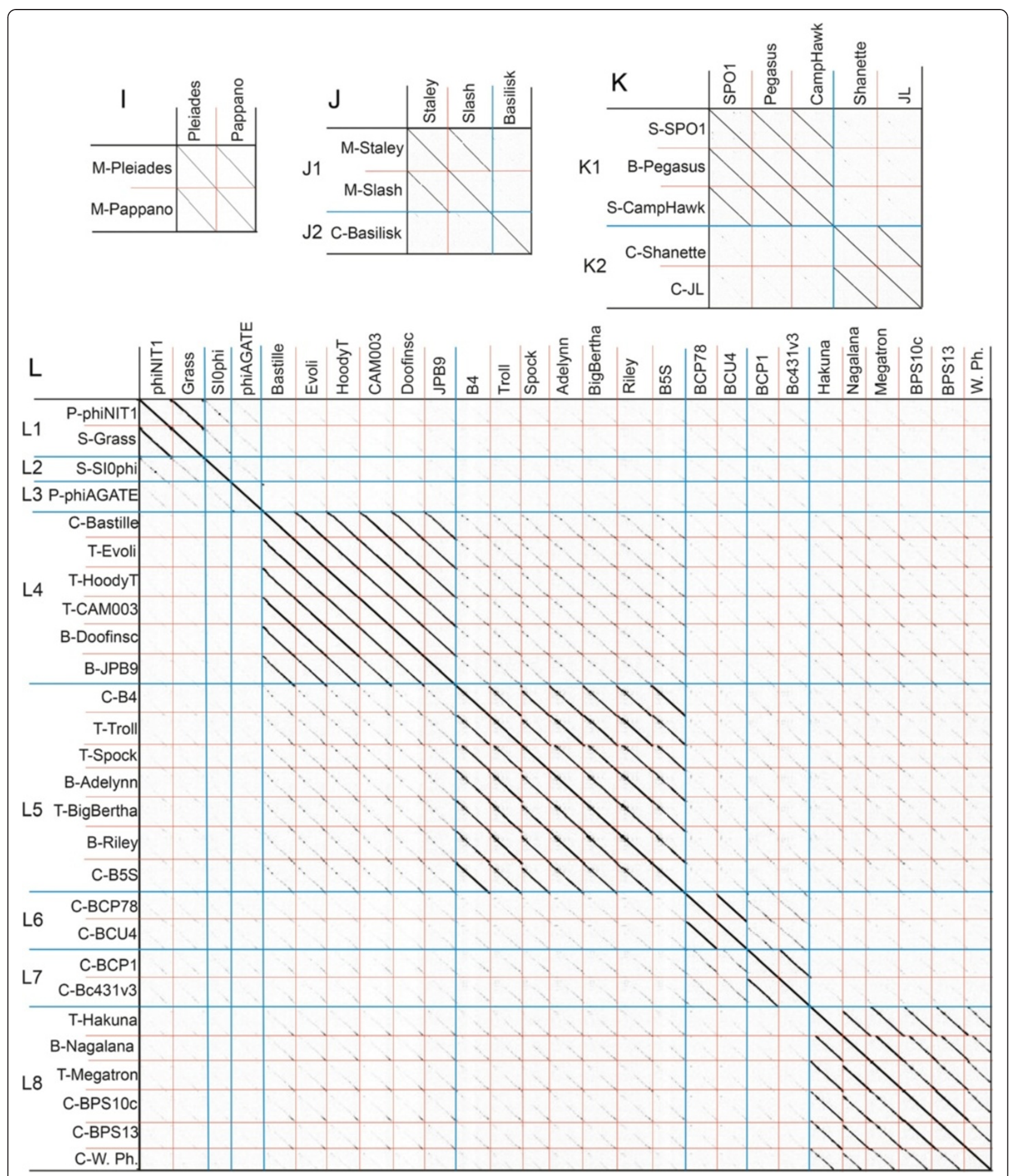

Figure 3 Analysis of fully sequenced Bacillus phage genomes belonging to clusters I through L reveals 13 subclusters. (I-L) Bacillus phage clusters I through L, respectively. Subcluster divisions are provided by blue lines and are indicated on the $Y$-axis when there are more than one per cluster. Individual phages are separated by red lines. Phage names are provided on the $X$-axis and $Y$-axis with host abbreviation from which the phages were isolated indicated on the Y-axis. Hosts abbreviations are Bacillus anthracis (A), Bacillus cereus (C), Bacillus sp. (B), Bacillus megaterium (M), Bacillus pumulis (P), Bacillus subtilis (S), Bacillus thuringiensis (T), and Bacillus weihenstephanensis MG1, (W). Dot plots were produced using Gepard [61]. 


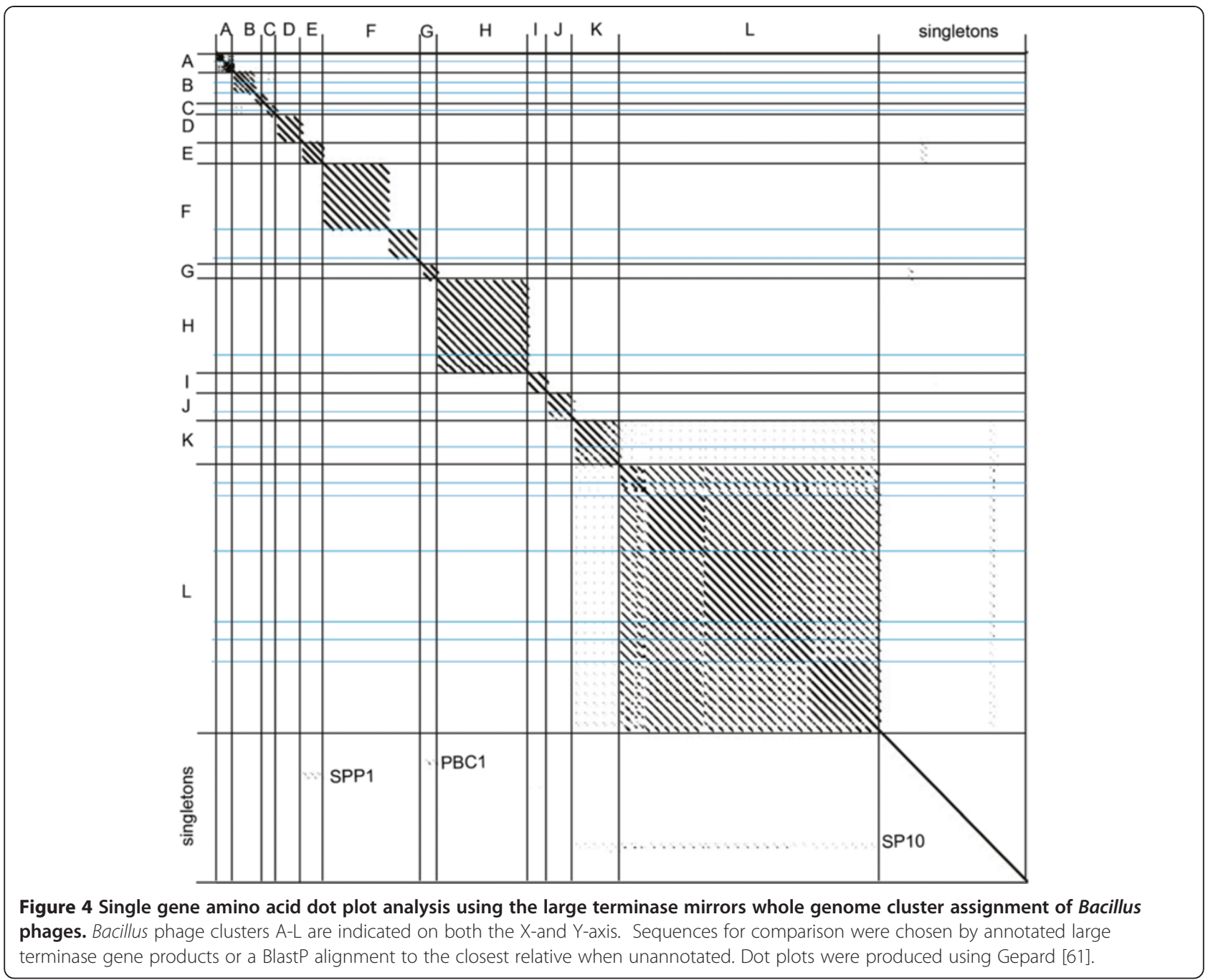

valuable insight into the replication strategy of these highly uncharacterized phages by comparing their terminases to those of well-characterized phages. Such comparisons have been used to determine the replication strategy of phages that infect Enterobacteriaceae hosts as well as phages that infect Paenibacillus larvae [71,72]. In our analysis, several Bacillus phages contain terminases that were similar to the well-characterized SPO1 Bacillus phage, suggesting that they replicate and package their DNA by a similar concatemer strategy resulting in non-permuted DNA with long, direct terminal repeats $[73,74]$. The cluster $\mathrm{K}$ phages had terminases of at least $87 \%$ similarity to SPO1 by BLASTP, while clusters $\mathrm{H}$ and L were weakly similar ( $\sim 43 \%$ and $\sim 56 \%$ similar respectively) and singleton phage SP10 was $68 \%$ similar. Cluster F, phBC6A52 and Bacillus virus 1 terminases have weak homology to the HK97 terminase (42\%- 45\% similarity) which packages by 3' cos ends, while phages of cluster J and singleton BanS-Tsamsa may have short
DTRs due to weak homology to the Clostridium phage C terminase ( $47 \%$ similarity) [75].

\section{Identification of two superclusters describing distantly} related phages through proteome conservation analysis In an effort to identify more distantly related phages belonging to "superclusters", we carefully analyzed faint nucleotide and proteome dot plot lines, CoreGenes percentages, and whole genome maps for intercluster relationships. The genomic map of a representative phage from each subcluster is given in Figure 6 as an example, however the larger phages are excluded due to space constraints (clusters A through $\mathrm{G}$ are shown). Because short regions of similarity are common among phages, phages had to have similarity in genome content and order (synteny) to be termed a supercluster. Table 3 lists the two superclusters identified in this analysis.

Faint lines can be seen in both the nucleotide and proteome dot plots between clusters E, F and G as well as 


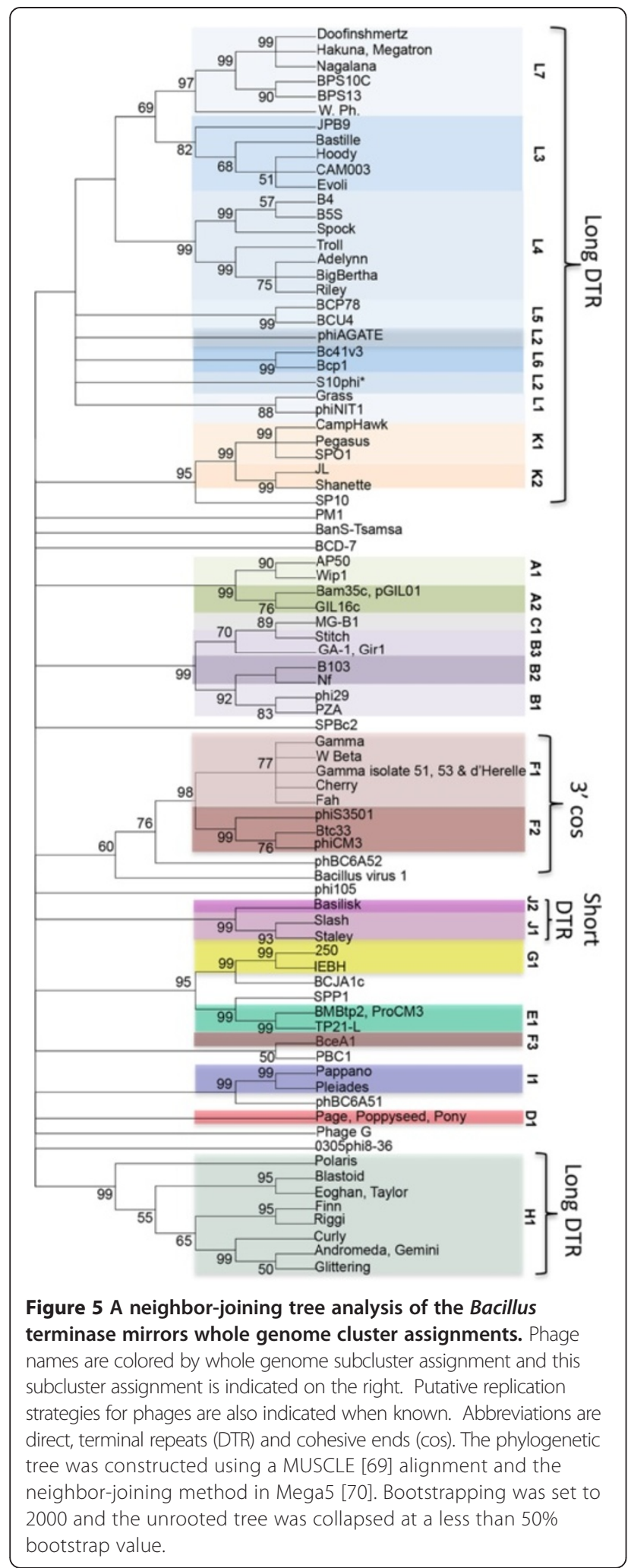

singleton PBC1. In addition, a similar genome content and order can be seen between these phages (for example phages TP21-L, Gamma and IEBH) where the first section of the chromosome contains phage structure and assembly genes and the last section harbors DNA metabolism genes (see Figure 6). These clusters also share an appreciable percentage of their proteome, with cluster E, F and G phages sharing $\sim 21 \%$ of their proteome with at least two members of another cluster. This observation suggests an ancient relationship that has diverged. Singleton PBC1 also shares $32 \%$ of its proteome with the cluster $\mathrm{G}$ phages. These proteins include the portal protein, the MCP, three putative minor capsid proteins, a putative minor structural protein, the TMP, a holin, a glutaredoxin-like protein and nine hypothetical proteins. We have termed this supercluster the d'Herelle-like supercluster after the founding phage.

Clusters K, L and singleton SP10 have similar relationships, with $\mathrm{K}$ and L cluster phages sharing up to $27 \%$ of their proteome. Singleton SP10 shares $29 \%$ of its proteome with cluster $\mathrm{K}$ phages and $\sim 24 \%$ with cluster $\mathrm{L}$ phages, including several structural proteins (portal protein, $\mathrm{MCP}$, minor structural protein, tail sheath, tail tube, tail assembly chaperone, tail lysin, tail fiber, tail baseplate and tail spike proteins), DNA replication proteins (DNA helicases, primase, endonuclease, exonuclease, and ribonuclotide reducatase), a peptidoglycan binding protein, a tRNA processing protein, several RNA polymerase sigma factors, and hypothetical proteins. Of interest, phage SP10 had previously been described as a SPO1-related phage by its discoverers [76]. This supercluster comprised of clusters K, L and singleton SP10 is termed the SPO1-like supercluster after this well-characterized B. subtilis phage.

Although faint lines can also be seen between the B and C clusters in some dot plots and $29 \%$ of the proteome is conserved between phages of this cluster, whole genome map displays different genome content and order (see Figure 6). In this case, rather than the phages displaying some similarity over a majority of the genomic map, they displayed similarity over a small portion. These phages were not included in a supercluster due to the very limited similarity as well as the differences in gene synteny, which suggest differences in phage lifestyles. These results reinforce the need for several analytical approaches in determining phage relationships.

\section{DNA metabolism, cell lysis, structural, and host gene products are well-conserved in Bacillus phages}

Phamerator [62] was used to determine the most highly conserved gene products within the 93 fully sequenced Bacillus phages, and the extent of conservation among the phages. Phamerator identified a total of 4,922 phams, or groups of proteins with homology to one another. Of these, 951 (19\%) had a predicted function and 3,971 (81\%) were uncharacterized. In addition, 3,058 (62\%) were orphams (phams containing a gene product from a single phage). This analysis confirms the highly diverse and uncharacterized nature of the Bacillus phages and 


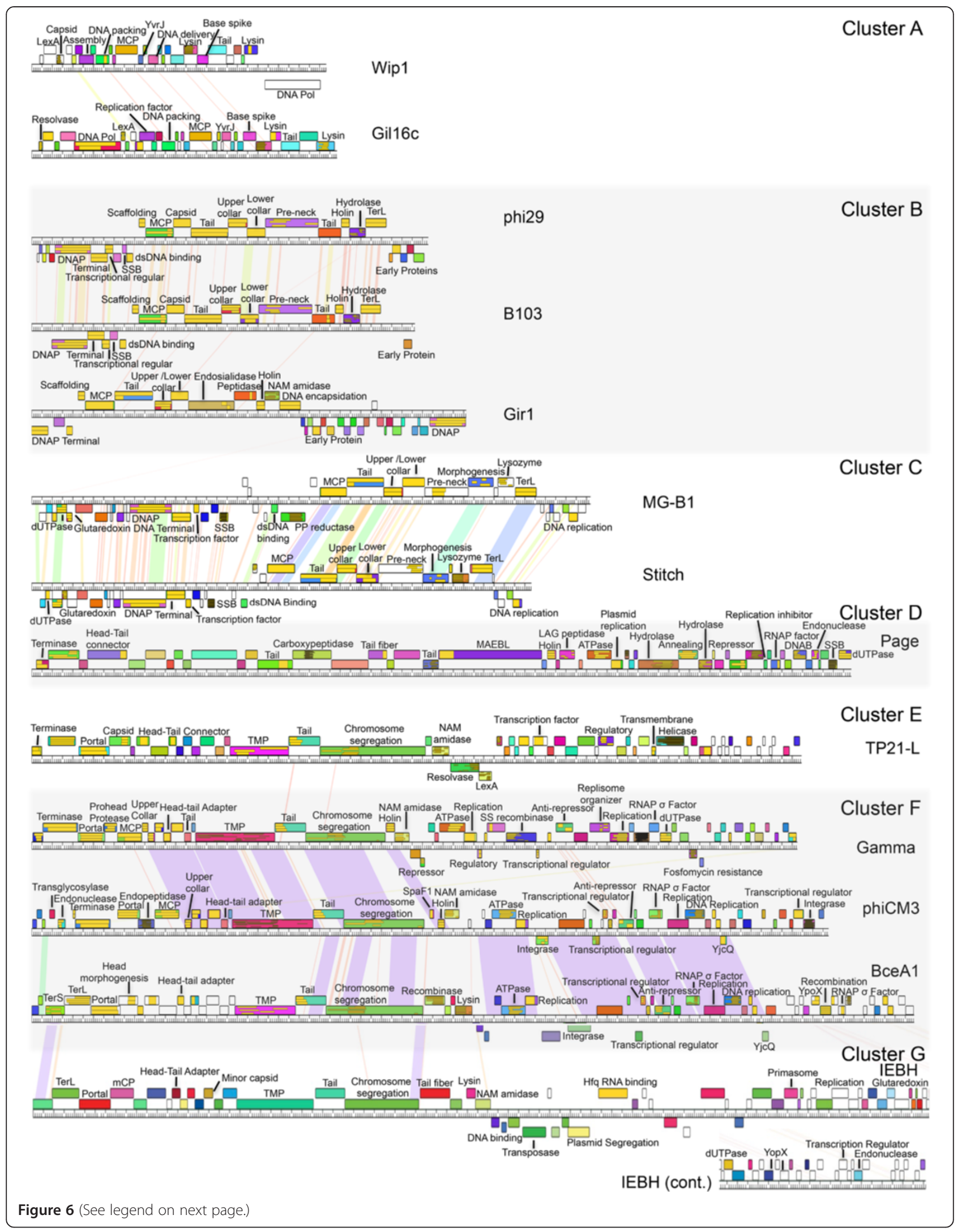


(See figure on previous page.)

Figure 6 A comparison of gene content and order within the Bacillus phage clusters reveals modularity and great diversity. Genome maps for representative phages from the subclusters within Bacillus phage clusters A-G are provided. Phages were mapped using Phamerator [62], where purple lines between phages denote regions of high nucleotide similarity and the ruler corresponds to genome base pairs. Boxes for gene products are labeled with predicted function, occasionally numbered, and colored to indicate similarity between the phages (E-value $<1 \mathrm{e}^{-4}$ ). Abbreviations are adenosine triphosphatase (ATPase), DnaB helicase (DNAB), double-stranded DNA binding (dsDNA binding), 2'-deoxyuridine 5'-triphosphatase (dUTPase), major capsid protein (MCP), N-acetyl-muramyl-L-alanine amidase (NAM amidase, pyrophosphate reductase (PP reductase) RNA polymerase (RNAP), sigma factor ( $\sigma$ factor), large terminase (TerL), small terminase (TerS), tape measure protein (TMP), pilus specific protein, ancillary protein involved in adhesion (SpaF1), single-stranded binding protein (SSB), single-strand recombinase (SS recombinase).

underscores the immense biological reservoir that is present. Table 4 (phams with predicted function) and Table 5 (phams with uncharacterized proteins) contain the highly conserved phams that have over 20 members. These phams are partitioned by their function as DNA replication/metabolism proteins, virion structure and assembly proteins, cell lysis proteins, or proteins involved in host function. It is important to note that there may be other proteins with similar function not included in a pham due to lack of homology.

\section{DNA replication/metabolism}

The most highly conserved Bacillus gene product is ribonucleotide reductase (RNR), with homologs found in 41 of the 93 phages and six phages have multiple homologs. RNR forms deoxyribonucleotides from ribonucleotides for DNA biosynthesis and is commonly found in lytic phages [77]. Other well-conserved proteins for nucleotide metabolism include a dihydrofolate reductase (conserved in 31 phages), thymidylate synthase (conserved in 28 phages), dNTP monophosphate kinase (conserved in 29 phages), ribonucleotide deoxyphosphate reductase (conserved in 27 phages) and a glutaredoxin (conserved in 24 phages). Many putative proteins involved in DNA replication and recombination were also identified including a DNA helicase (conserved in 33 phages), replicative helicase (conserved in 27 phages), DNA exonuclease and endonuclease (conserved in 33 and 32 phages, respectively), DNA polymerase (conserved in 27 phages), RecA homolog (conserved in 27 phages), and a DNA primase (conserved in 27 phages). These results underscore the vital nature of efficient nucleotide metabolism in the propagation of lytic phages .

\section{Virion structure and assembly proteins}

The structural and assembly proteins of the virion are also highly conserved gene products within the Bacillus phages, with phams consisting of a MCP, large terminase, portal protein, capsid structural protein, baseplate, tail sheath, and a tail lysin all having homologs in 33 of the 93 phages (35\%). In addition, a procapsid protease, tail fiber, tail assembly chaperone, virion structural protein and a baseplate have homologs in at least 27 of the 93 phages. These structural proteins are conserved among phages that are known myoviruses and siphoviruses, although the podoviruses and tectiviruses should also contain an MCP, portal protein and terminase. We were able to identify a large terminase for all of the Bacillus phages, meaning that these gene products had homologs that were somewhat characterized, but not homologous to the prevalent Pham. In contrast, we were unable to identify an MCP for $19 \%$ of the Bacillus phages, suggesting that homologs have not been described and emphasizing the need for further characterization of Bacillus phages. In support of this finding, recent studies have shown that MCP's bearing no amino acid sequence similarity can harbor similar folds $[21,22,78-80]$ hampering identification by sequence alone.

\section{Cell lysis}

Cell lysis proteins are vital to the phage lifecycle, allowing them to exit the cell and infect other hosts. Three cell lysis proteins were well-conserved including a mureintransglycosylase (conserved in 33 phages) and two holins (each conserved in 27 phages).

\section{Host functions/pathogenesis}

Several gene products that are likely to regulate host functions were also highly conserved in Bacillus phages. A protein containing a bacterial SH3-like domain was identified in 28 of the 93 phages, including phages from cluster D, F, G, and L. The function of this protein is unknown but the SH3 domain is thought to mediate the assembly of large multiprotein complexes [23]. In addition, the cAMP regulatory protein (CRP) is found in 27 phages and a sigma-70 factor in 19 phages, which may both be used to control the expression of host carbon metabolism

Table 3 Bacillus phage superclusters describe distantly related phages sharing significant proteome conservation

\begin{tabular}{lcc}
\hline Supercluster & Phages & \% Proteome conserved \\
\hline d'Herelle-like & Clusters E, F and G, phage PBC1 & $21 \%(E, F$ and G), 32\% (G and PBC1) \\
SPO1-like & Clusters K, Cluster L & $27 \%$ \\
\hline
\end{tabular}

*Percent proteome conserved is the percentage conserved between two phages within different cluster as determined by CoreGenes. 
Table 4 Common Bacillus phage proteins of predicted function with over 20 members

\begin{tabular}{|c|c|c|c|c|}
\hline Pham \#* & Domain/function & \# Members & \# Phages & Phages (cluster or phage name) \\
\hline \multicolumn{5}{|r|}{ Dna Replication/metabolism } \\
\hline 236 & DNA Polymerase & 52 & 33 & $\mathrm{~K}, \mathrm{~L} 1, \mathrm{~L} 2, \mathrm{~L} 3, \mathrm{~L} 4, \mathrm{~L} 5, \mathrm{~L} 6, \mathrm{~L} 8, \mathrm{SP} 10, \mathrm{BC} 431 \mathrm{~V} 3$ \\
\hline 247 & $\begin{array}{l}\text { Ribonucleotide } \\
\text { reductase }\end{array}$ & 47 & 41 & I,J,K1 L,L,030548-36,L6,L3,BCD7,SP10,BanSTsamsa,SPB2 \\
\hline 261 & Helicase & 36 & 33 & $L, K, S P 10$ \\
\hline 256 & Exonuclease & 34 & 33 & $L, K, S P 10$ \\
\hline 257 & Nuclease & 33 & 32 & $\mathrm{~K}, \mathrm{~L} 1, \mathrm{~L} 2, \mathrm{~L} 3, \mathrm{~L} 4, \mathrm{~L} 5, \mathrm{~L} 6, \mathrm{~L} 7 \mathrm{BPS10C}, \mathrm{SP} 10, \mathrm{~W} . \mathrm{PH}$. \\
\hline 101 & $\begin{array}{l}\text { Dihydrofolate } \\
\text { Reducatase }\end{array}$ & 32 & 31 & Hakuna,Nagalana,Megatron G,J2,L,BCD7,BanS-Tsamsa \\
\hline 98 & $\begin{array}{l}\text { Thymidylate } \\
\text { Synthase }\end{array}$ & 30 & 28 & $\mathrm{~L}, \mathrm{BCD} 7$ \\
\hline 99 & dNTP MonoP Kinase & 30 & 29 & $\mathrm{I}, \mathrm{L}$ \\
\hline 246 & $\begin{array}{l}\text { Ribonucleotide diP } \\
\text { Reduct. }\end{array}$ & 29 & 27 & J1,K1,L4,L5,L6,L8,0305phi8-36 \\
\hline 232 & DNA Polymerase III & 29 & 27 & L \\
\hline 238 & Histone & 28 & 27 & $\mathrm{~L}$ \\
\hline 252 & $\stackrel{\mathrm{dU}}{\text { Nucleotidylhydrolase }}$ & 28 & 27 & L \\
\hline 258 & $\begin{array}{l}\text { Replicative DNA } \\
\text { Helicase }\end{array}$ & 28 & 27 & $\mathrm{~L}$ \\
\hline 229 & RecA & 28 & 27 & L \\
\hline 254 & DNA Primase & 28 & 27 & $\mathrm{~L}$ \\
\hline 227 & Sigma Factor & 28 & 27 & L \\
\hline 244 & Glutaredoxin & 25 & 24 & $\mathrm{L1} 1, \mathrm{L2}, \mathrm{L} 4, \mathrm{~L} 5, \mathrm{~L} 6, \mathrm{SPBC} 2, \mathrm{BPS10c}, \mathrm{BPS} 13$ \\
\hline 370 & $\begin{array}{l}\text { DNA Segregation } \\
\text { ATPase }\end{array}$ & 24 & 24 & Megatron,Nagalana,W.Ph \\
\hline 740 & $\begin{array}{l}\text { Met S- } \\
\text { methyltransferase }\end{array}$ & 24 & 16 & $\begin{array}{c}\text { E,F1,Andromeda,Gemini,Glittering,Curly,Eoghan,Taylor, Riggi,Blastoid,Finn,BV1,PL1,E1, } \\
\text { phIS3501,phBC6A51 L5,L8,Bastille,Doofenshmirtz,JPB9,W.Ph }\end{array}$ \\
\hline \multicolumn{5}{|r|}{ Virion structure and assembly } \\
\hline 278 & $\begin{array}{l}\text { Tail Assembly } \\
\text { Chaperone }\end{array}$ & 56 & 27 & $\mathrm{~L}$ \\
\hline 274 & Tail Fiber & 43 & 29 & J2,L, BanS-Tsamsa \\
\hline 5174 & Phage Terminase & 41 & 33 & K,L,SP10 \\
\hline 264 & Adsorption Tail & 36 & 33 & $\mathrm{~L} 1, \mathrm{~L} 2, \mathrm{~L} 3, \mathrm{~L} 5, \mathrm{~L} 6, \mathrm{~L} 8, \mathrm{Bc} 431 \mathrm{v} 3$ \\
\hline 295 & Portal Protein & 35 & 33 & K,L,SP10 \\
\hline 291 & MCP & 35 & 33 & K,L,SP10 \\
\hline 276 & Tail Lysin & 35 & 33 & $\mathrm{~K}, \mathrm{~L}, \mathrm{SP} 10$ \\
\hline 266 & Baseplate & 34 & 33 & K,L,SP10 \\
\hline 283 & Structural Protein & 34 & 33 & K,L,SP10 \\
\hline 284 & Tail Sheath & 34 & 33 & K,L,SP10 \\
\hline 293 & Prohead Protease & 33 & 32 & $\mathrm{~K}, \mathrm{L2}, \mathrm{L} 3, \mathrm{L4}, \mathrm{L} 5, \mathrm{~L} 6, \mathrm{~L} 7, \mathrm{~L} 8$, phiNIT1,SP10 \\
\hline 273 & Tail Lysin & 32 & 28 & L,BanS-Tsamsa \\
\hline 277 & Structural Protein & 30 & 29 & L,SP10 \\
\hline 267 & Baseplate & 28 & 27 & L \\
\hline
\end{tabular}


Table 4 Common Bacillus phage proteins of predicted function with over 20 members (Continued)

\begin{tabular}{|c|c|c|c|c|}
\hline \multicolumn{5}{|c|}{ Cell lysis proteins } \\
\hline 282 & $\begin{array}{c}\text { Murein } \\
\text { Transglycosylase }\end{array}$ & 34 & 33 & K1,L,0305甲8-36,SP10,BanS-Tsamsa \\
\hline 226 & Holin & 28 & 27 & $L$ \\
\hline 198 & Holin & 28 & 27 & L \\
\hline \multicolumn{5}{|c|}{ Gene regulation/host functions } \\
\hline 35 & Bacterial SH3-like & 29 & 28 & D,F1,G,L5,L8,BanS-Tramsa,Doonfenshmirtz,ФCM3 \\
\hline 222 & Metallophosphatase & 28 & 27 & $L$ \\
\hline 260 & $\begin{array}{c}\text { CAMP Regulatory } \\
\text { Protein }\end{array}$ & 28 & 27 & $L$ \\
\hline 155 & Beta Lactamase & 26 & 25 & L4,L5,L6,L7,L8,BanS-Tsamsa \\
\hline 787 & Methyltransferase & 20 & 19 & $\llcorner 4, L 5, L 8$ \\
\hline 676 & Sigma 70 Factor & 20 & 19 & $\lfloor 4, L 5, L 8$ \\
\hline
\end{tabular}

Abbreviations include deoxynucleotide monophosphate kinase (dNTP MonoP Kinase), ribonucleotide diphosphate reducatase (Ribonucleotide diP Reduct.), deoxyuridine nucleotidylhydrolase (dU Nucleotidylhydrolase), Methionine A-methyltransferase (Met A-methyltransferase), and major capsid protein (MCP). Gene products are given and are organized by basic function (DNA Replication/Metabolism, Virion Structure and Assembly, Cell Lysis Proteins, or Gene Regulation/Host Functions).

*Pham \#'s are specific to this analysis and are larger than the total number of phams due to assignment by Phamerator [62].

genes which can contribute to bacterial virulence [81]. An FtsK/SpoIIIE-like cell division protein (gp22 in phage Cherry) was conserved in 24 of the phages (pham370). This protein may control host transition into the sporulation state, contributing to the environmental fitness of $B$. anthracis [29].

There are several other proteins that are less conserved that may contribute to host pathogenesis. Three Bacillus phages (JL, Shanette and SP10) harbor a dUTPase, which are common in many bacteriophages and have been shown to function as $\mathrm{G}$ protein-like regulators required for the transfer of staphylococcal virulence factors [82,83]. Five Bacillus phages (SPO1, CampHawk, Pegasus, JL, and Shanette), encode a Pho-H like protein that aids in bacterial survival under phosphate starvation $[84,85]$. Genes belonging to the phosphate regulon are reportedly very common in marine phages $(40 \%)$ while they are less common in non-marine phages (4\%) [86], in good agreement with our identification of $\mathrm{PhoH}$ in $5.4 \%$ of the Bacillus phages.

Subcluster F1 phages encode resistance to the soil antibiotic fosfomycin, which may account for the resistance reported for B. anthracis strains [29]. In addition, $\mathrm{JL}$ and Shanette both encode the tellurium resistance proteins TerE and TerC. Tellurium oxyanion $\left(\mathrm{TeO}_{3}^{2-}\right)$ has been used in the treatment of mycobacterial infections and resistance is a feature of many pathogenic bacteria. In fact, resistance is commonly used for the identification and isolation of Shiga toxin-producing E. coli [87].

\section{The comparison of subcluster and bacterial host reveals evolutionary boundaries}

The Bacillus hosts in this study can be assembled into two separate groups by relatedness, and this evolutionary boundary may define phage boundaries and predict barriers for pathogenic gene transfer. B. subtilis, B. megaterium and $B$. pumulis are more closely related to each other than they are to the Bacillus cereus group of bacteria, comprised of $B$. cereus, B. anthracis, B. thuringiensis, B. weihenstephanensis, B. mycoides and B. pseudomycoides [88,89]. To determine if there are such boundaries between phages and their hosts, the host from which each phage was isolated was compared within each cluster and subcluster.

The cluster to bacterial host relationship was somewhat ambiguous, with $67 \%$ of clusters populated by phages from only closely related Bacillus species (clusters A, B, C, D, E, F, G, and I) and others (clusters H, J, $\mathrm{K}$ and $\mathrm{L}$ ) harboring phages from more distantly related Bacillus species (see Table 2). However, within these latter clusters there is a clear division at the subcluster level in that B. subtilis, B. pumulis, and B. megaterium phages always fall into a separate subcluster than phages that infect B. cereus, B. thuringiensis, B. anthracis, and $B$. weihenstephanensis. More phages are clearly needed to understand the host diversity within clusters, however, because only four clusters contain phages from diverse hosts (phages from both a B. subtilis, B. pumulis, B. megaterium host and from a Bacillus cereus group host). In addition, this analysis was performed using only the host from which the phage was isolated since the host range of most of these phages is unknown. Host range studies will provide greater insight. For example, a recent finding that phage BPC78 infects both $B$. cereus and $B$. subtilis suggests that some phages are able to overcome this apparent host boundary [44].

The subcluster to host analysis also suggests a closer relationship between the $B$. thuringiensis and $B$. cereus species when compared to $B$. anthracis, since there is a 
Table $\mathbf{5}$ Common Bacillus phage proteins of uncharacterized function with over $\mathbf{2 0}$ members

\begin{tabular}{|c|c|c|c|}
\hline Pham \#* & \# Members & \# Phages & Phages (cluster or phage name) \\
\hline \multicolumn{4}{|c|}{ Uncharacterized proteins } \\
\hline 154 & 40 & 23 & L5,L6,L7,M8,Bc431v3 \\
\hline 248 & 34 & 33 & $\mathrm{~K}, \mathrm{~L}, \mathrm{M}, \mathrm{SP} 10$ \\
\hline 289 & 34 & 33 & L3,L5,L7,M8,B4,Troll,Spock,Adelynn,BigBertha,Riley \\
\hline 4507 & 30 & 28 & $\mathrm{~K}, \mathrm{~L} 1, \mathrm{~L} 2, \mathrm{~L} 4, \mathrm{M} 7$ \\
\hline 265 & 29 & 28 & $\mathrm{~K} 1, \mathrm{~L} 1, \mathrm{~L} 2, \mathrm{~L} 4, \mathrm{~L} 5, \mathrm{~L} 6, \mathrm{~L} 7, \mathrm{M}$ \\
\hline 288 & 29 & 28 & I1,L,M \\
\hline 268 & 28 & 27 & $L, M$ \\
\hline 269 & 28 & 27 & $L, M$ \\
\hline 272 & 28 & 27 & $L, M$ \\
\hline 88 & 28 & 27 & $L, M$ \\
\hline 92 & 28 & 27 & $\mathrm{~L} 1, \mathrm{~L} 2, \mathrm{~L} 3, \mathrm{~L} 4, \mathrm{~L} 5, \mathrm{~L} 6, \mathrm{M}$ \\
\hline 194 & 28 & 27 & $L, M$ \\
\hline 195 & 28 & 27 & $L, M$ \\
\hline 208 & 28 & 27 & $L, M$ \\
\hline 235 & 28 & 27 & $L, M$ \\
\hline 239 & 28 & 27 & $L, M$ \\
\hline 286 & 28 & 27 & $L, M$ \\
\hline 5235 & 27 & 27 & $L, M$ \\
\hline 302 & 27 & 27 & $L, M$ \\
\hline 5250 & 27 & 27 & $L, M$ \\
\hline 86 & 27 & 26 & $L, M$ \\
\hline 200 & 27 & 26 & L,W.Ph.,Hakuna,Nagalana,Megatron,BPS10C \\
\hline 225 & 27 & 26 & $\mathrm{~L} 1, \mathrm{~L} 2, \mathrm{~L} \mathrm{~L}, \mathrm{~L} 4, \mathrm{M} 7$ \\
\hline 228 & 27 & 26 & $L, M$ \\
\hline 255 & 27 & 26 & $\mathrm{~L} 1, \mathrm{~L} 2, \mathrm{~L} 4, \mathrm{~L} 5, \mathrm{~L} 6, \mathrm{~L} 7, \mathrm{M}$ \\
\hline 287 & 27 & 26 & L,W.Ph,Hakuna,Nagalana,BPS13,Megatron \\
\hline 296 & 27 & 26 & L,W.Ph,Hakuna,Nagalana,BPS13,Megatron \\
\hline 5247 & 26 & 26 & L4,L5,L6,L7,W.Ph.,Hakuna,Nagalana,Megatron,BPS10C \\
\hline 5240 & 26 & 26 & $\mathrm{L1}, \mathrm{L} 4, \mathrm{~L} 5, \mathrm{~L} 6, \mathrm{~L} 7, \mathrm{M}$ \\
\hline 5190 & 26 & 27 & $\mathrm{~L} 1, \mathrm{~L} 2, \mathrm{~L} 5, \mathrm{~L} 6, \mathrm{~L} 7, \mathrm{M}$ \\
\hline 244 & 24 & 24 & $\mathrm{~L} 5, \mathrm{~L} 6, \mathrm{~L} 7, \mathrm{M}$ \\
\hline 251 & 24 & 23 & $\mathrm{~L} 5, \mathrm{~L} 6, \mathrm{~L} 7, \mathrm{M}$ \\
\hline 4539 & 24 & 22 & $J 2, \mathrm{~L} 5, \mathrm{~L} 6, \mathrm{~L} 7, \mathrm{M}, \mathrm{PBC} 1$ \\
\hline 4492 & 24 & 24 & $\llcorner 4, L 5, L 6, L 7, M$ \\
\hline 4495 & 24 & 23 & $\llcorner 4, L 5, L 6, L 7, M 8, B C 431$ \\
\hline 4496 & 23 & 22 & L5,L6,M8,BC431v \\
\hline 280 & 23 & 21 & $\mathrm{~L} 5, \mathrm{~L} 6, \mathrm{~L} 7, \mathrm{M} 8$ \\
\hline 33 & 22 & 21 & $\mathrm{D}, \mathrm{F}, \mathrm{G}, \mathrm{J} 2, \mathrm{~K} 2, \mathrm{SP} 10$, phBC6A51,BceA1 \\
\hline 781 & 22 & 21 & $L 5, L 6, M$ \\
\hline \multirow[t]{2}{*}{245} & 22 & 21 & K2,Adelynn,BigBertha,Spock,Riley,BCP1,Hakuna,Nagalana, Megatron, Doofenshmirtz, \\
\hline & & - & Evoli, HoodyT, CAM003 ,IEBH ,JPB9 \\
\hline 87 & 22 & 21 & L1,L2,L3,L4,M7,Troll,Spock,Adelynn,BigBertha,Riley,L7,BPS10C,BPS13, \\
\hline
\end{tabular}




\begin{tabular}{llll}
\hline & - & Nagalana,Megatron,Bastille,Evoli,HoodyT,CAM003,Doofenshmirtz \\
176 & 20 & 20 & L,M7,Bastille,CAM003,HoodyT,JPB9,Evoli \\
180 & 20 & 19 & L,M7,Bastille,CAM003,HoodyT,JPB9,Evoli \\
618 & 20 & 22 & $L 5, L 6, M 8$ \\
4500 & 20 & 20 & $L 5, L 6, M 8$ \\
174 & 20 & 19 & $L 5, L 6, M 8$ \\
4538 & 20 & 20 & $L 5, L 6, M 8$ \\
303 & 20 & - & $L 5, L 6, M 8$ \\
224 & 20 & 20 L5,L6,M8 \\
\hline
\end{tabular}

*Pham \#'s are specific to this analysis and are larger than the total number of phams due to assignment by Phamerator [62].

subcluster division between $B$. anthracis phages and those that infect $B$. thuringiensis or B. cereus (see Figure 2, clusters $\mathrm{A}$ and F). This apparent evolutionary separation is surprising given the recent report of five phages that infect $B$. anthracis and B. thuringiensis as well as the B. cereus host on which they were isolated (BanS-Tsama [59], Bc431v3 [90], and JL, Shanette, and Basilisk [21]).

\section{Conclusions}

Phages are intimately linked to the ecology and evolution of their hosts, making phage characterization vital to understanding the diversity and evolution of the $\mathrm{Ba}$ cillus genus. Herein we described the comparison of 93 fully sequenced Bacillus phages and their grouping into 12 clusters, 14 singletons and 28 subclusters (see Tables 1 and 2). In addition, two groups of more distantly-related phages were identified and termed "superclusters", namely the SPO1-like and d'Herelle-like phages. This analysis of Bacillus phages may aid in understanding newly isolated phages as well as the enormous complexity of tailed phages. It may also serve as a reference for comparisons to phages that infect other genera. The only other such analyses are of 491 phages that infect Mycobacterium and of 337 phages that infect the Enterobacteriaceae family. Hatfull et al. grouped the Mycobacteriophages into 17 "clusters" of related phages (A-Q) and 14 singleton clusters [13], while Grose and Casjens grouped the Enterobacteriaceae phages into 38 clusters of related phages and 18 singleton clusters [14]. In contrast to both of these phage groups, the Bacillus singletons outnumber the Bacillus clusters, presumably due to the decreased number of total phages isolated (93 phages as compared to 491 or 337). It should also be noted that additional Bacillus phage isolation will most likely require future revision of these cluster assignments as phages may be isolated that unite clusters.

Our analysis revealed several clusters of highly related phages (clusters $\mathrm{C}, \mathrm{D}, \mathrm{E}, \mathrm{H}$ and I), and other clusters that contained very diverse phages (A, B, F, G, J, K and L) (see Figures 2 and 3). Due to the low number of phages isolated and the apparent expected diversity, it is currently unknown if these differences reflect differences in phage lifestyles, or if they occur due to sampling biases. Our analysis also revealed the need for using several analytical techniques to group phages, since one technique may suggest apparent relatedness that is weak by other techniques. For example, the B and C clusters share 29\% proteome conservation as analyzed by CoreGenes and faint lines of similarity can be seen in genomic dot plots. However, analysis of the overall genome synteny suggests they are more diverse in lifestyle than phages that typically form clusters/superclusters (see Figure 6).

In addition to whole genome analysis, analysis of Bacillus phage gene products further underscores the enormity of Bacillus phage diversity, with $81 \%$ of protein phams $(3,971)$ consisting of uncharacterized proteins. In addition, $\sim 19 \%$ of MCPs were unannotated and unidentifiable, highlighting the uncharacterized nature of these phages. Since several phams of known function were identified that may contribute to host pathogenicity, understanding these uncharacterized phams is critical to understanding the evolution of pathogenic Bacillus strains.

The analysis of Bacillus phage evolutionary boundaries suggests that close phage relationships (defined by subclusters) are restricted by the relatedness of the host, with the phages that infect the Bacillus cereus group of phages more similar than those that infect B. subtilis, $B$. megaterium and P. pumulis. This analysis of host vs. cluster is not only beneficial to understanding the evolution of Bacillus species but may indicate phage clusters more suitable for targeted phage therapy of pathogenic $B$. cereus and B. anthracis strains.

\section{Methods}

Computational analysis and genomic comparison

Bacillus phage sequences were retrieved from GenBank and the Bacillus Phage Database at PhagesDB.org as well as by contact with the authors of this website. To ensure retrieval of all Bacillus phages from GenBank, the major capsid protein (MCP) from at least one phage in each 
cluster was used to retrieve all phages with similar MCP sequence via TBLASTN [91]. Genomic maps of each phage were prepared using Phamerator [62], an opensource program designed to compare phage genomes. Phamerator was also used to calculate the percent G/C, number of ORFs and protein families or phams. The percentage of the proteome conserved was identified using the program CoreGenes 3.0 at the default BLASTP threshold of $75[63,64]$, while average nucleotide identity (ANI) was calculated by Kalign [92]. Dot plots were generated using Gepard [61]. For ease in dot plot analysis, long direct terminal repeats were removed from some phages, other phage genomes were reverse complemented, and new bp one calls were made to re-orient according to the majority of phages within a cluster. In addition, a portion of the PZA nucleotide sequence was reverse complemented to allow alignment with other phages of the cluster. Whole genome amino acid sequences were retrieved from Phamerator [62].

The terminase phylogenetic tree was constructed using a MUSCLE [69] alignment and the neighbor-joining method in Mega5 [70]. Bootstrapping was set to 2000 and the unrooted tree was collapsed at a less than 50\% bootstrap value. Sequences for comparison were chosen by annotated large terminase gene products or a BlastP alignment to the closest relative when unannotated.

\begin{abstract}
Abbreviations
B. anthracis, A: Acterial species abbreviations: Bacillus anthracis; B. cereus, C: Bacillus cereus; B: Bacillus sp; B. megaterium, M: Bacillus megaterium; $B$. pumulis, P: Bacillus pumulis; B. subtilis, S: Bacillus subtilis; B.thuringiensis, T: Bacillus thuringiensis; B. weihenstephanensis, W: Bacillus weihenstephanensis MG1; Tectiviridae (T): Viral family abbreviations; P: Podoviridae; S: Siphoviridae; M: Myoviridae; MCP: Phage protein abbreviations: Major Capsid Protein; TMP: Tape Measure Protein; ANI: Other: Average Nucleotide Identity; bp: Base pair; kbp: Kilobase pair; ORF: Open Reading Frame; pham: Phage protein family identified by Phamerator; UK: Unknown.
\end{abstract}

\section{Competing interests}

The authors declare that they have no competing interests.

\section{Authors' contributions}

JHG wrote the manuscript, analyzed data and produced tables and figures, GLJ compiled the Bacillus Phamerator database, produced Tables 4 and 5 and Figure 5. All authors edited the manuscript. All authors read and approved the final manuscript.

\section{Acknowledgements}

The authors thank Dr. Steven Cresawn and BYU undergraduate Bryan Merrill for aiding in the set-up of the Bacillus Phamerator database and Byron Doyle at Brigham Young University for aid in running the computer code on local computers. We are grateful for the BYU undergraduate student researcher Joshua Fisher who aided collection of related genomes for analysis.

Received: 7 June 2014 Accepted: 24 September 2014

Published: 4 October 2014

\section{References}

1. Bergh $\mathrm{O}$, Borsheim $\mathrm{KY}$, Bratbak $\mathrm{G}$, Heldal M: High abundance of viruses found in aquatic environments. Nature 1989, 340(6233):467-468.

2. Brussow H, Hendrix RW: Phage genomics: small is beautiful. Cell 2002, 108(1):13-16.
3. Hambly E, Suttle CA: The viriosphere, diversity, and genetic exchange within phage communities. Curr Opin Microbio/ 2005, 8(4):444-450.

4. Wilhelm SW, Jeffrey WH, Suttle CA, Mitchell DL: Estimation of biologically damaging UV levels in marine surface waters with DNA and viral dosimeters. Photochem Photobiol 2002, 76(3):268-273.

5. Wommack KE, Colwell RR: Virioplankton: viruses in aquatic ecosystems. Microbiol Mol Biol Rev 2000, 64(1):69-114.

6. Brovko LY, Anany H, Griffiths MW: Bacteriophages for detection and control of bacterial pathogens in food and food-processing environment. Adv Food Nutr Res 2012, 67:241-288.

7. Chan BK, Abedon ST, Loc-Carrillo C: Phage cocktails and the future of phage therapy. Future Microbiol 2013, 8(6):769-783.

8. Haque A, Tonks NK: The use of phage display to generate conformationsensor recombinant antibodies. Nat Protoc 2012, 7(12):2127-2143.

9. Henry M, Debarbieux L: Tools from viruses: bacteriophage successes and beyond. Virology 2012, 434(2):151-161.

10. Murphy KC: Phage recombinases and their applications. Adv Virus Res 2012, 83:367-414.

11. Sharma M: Lytic bacteriophages: potential interventions against enteric bacterial pathogens on produce. Bacteriophage 2013, 3(2):e25518.

12. Singh A, Poshtiban S, Evoy S: Recent advances in bacteriophage based biosensors for food-borne pathogen detection. Sensors (Basel) 2013, 13(2):1763-1786.

13. Hatfull GF: Mycobacteriophages: windows into tuberculosis. PLoS Pathog 2014, 10(3):e1003953.

14. Grose JH, Casjens SR: Understanding the enormous diversity of bacteriophages: the tailed phages that infect the bacterial family Enterobacteriaceae. Virol J 2014, 468-470C:421-443.

15. Hatfull GF, Jacobs-Sera D, Lawrence JG, Pope WH, Russell DA, Ko CC, Weber RJ, Patel MC, Germane KL, Edgar RH, Hoyte NN, Bowman CA, Tantoco AT, Paladin EC, Myers MS, Smith AL, Grace MS, Pham TT, O'Brien MB, Vogelsberger AM, Hryckowian AJ, Wynalek JL, Donis-Keller H, Bogel MW, Peebles CL, Cresawn SG, Hendrix RW: Comparative genomic analysis of 60 Mycobacteriophage genomes: genome clustering, gene acquisition, and gene size. J Mol Biol 2010, 397(1):119-143.

16. Pope $\mathrm{WH}$, Jacobs-Sera D, Russell DA, Peebles CL, Al-Atrache Z, Alcoser TA, Alexander LM, Alfano MB, Alford ST, Amy NE, Anderson MD, Anderson AG, Ang AA, Ares M Jr, Barber AJ, Barker LP, Barrett JM, Barshop WD, Bauerle CM, Bayles IM, Belfield KL, Best AA, Borjon A Jr, Bowman CA, Boyer CA, Bradley KW, Bradley VA, Broadway LN, Budwal K, Busby KN, et al: Expanding the diversity of mycobacteriophages: insights into genome architecture and evolution. PLoS One 2011, 6(1):e16329.

17. Schuch R, Pelzek AJ, Kan S, Fischetti VA: Prevalence of Bacillus anthracis-like organisms and bacteriophages in the intestinal tract of the earthworm Eisenia fetida. App/ Environ Microbiol 2010, 76(7):2286-2294.

18. Nagy E, Pragai B, Ivanovics G: Characteristics of phage AP50, an RNA phage containing phospholipids. J General Virol 1976, 32(1):129-132.

19. Verheust C, Fornelos N, Mahillon J: GIL16, a new gram-positive tectiviral phage related to the Bacillus thuringiensis GIL01 and the Bacillus cereus pBClin15 elements. J Bacterio/ 2005, 187(6):1966-1973.

20. Verheust C, Jensen G, Mahillon J: pGIL01, a linear tectiviral plasmid prophage originating from Bacillus thuringiensis serovar israelensis. Microbiology 2003, 149(Pt 8):2083-2092.

21. Grose JH, Belnap DM, Jensen JD, Mathis AD, Prince JT, Burnett SH, Breakwell DP: The genomes, proteomes and structure of three novel phages that infect the bacillus cereus group and carry putative virulence factors. J Virol 2014. In Press.

22. Zhang X, Guo H, Jin L, Czornyj E, Hodes A, Hui WH, Nieh AW, Miller JF, Zhou ZH: A new topology of the HK97-like fold revealed in Bordetella bacteriophage by cryoEM at 3.5 A resolution. elife 2013, 2:e01299.

23. Kay BK: SH3 domains come of age. FEBS Lett 2012, 586(17):2606-2608.

24. Yoshikawa $\mathrm{H}$, Ito J: Terminal proteins and short inverted terminal repeats of the small Bacillus bacteriophage genomes. Proc Natl Acad Sci U S A 1981, 78(4):2596-2600.

25. Redondo RA, Kupczok A, Stift G, Bollback JP: Complete genome sequence of the novel phage MG-B1 infecting bacillus weihenstephanensis. Genome Announcements 2013, 1:3.

26. Lopez MS, Hodde MK, Chamakura KR, Kuty Everett GF: Complete genome of bacillus megaterium podophage page. Genome Announcements 2014, 2:2

27. Khatemi BE, Chung On CC, Chamakura KR, Kuty Everett GF: Complete genome of bacillus megaterium podophage pony. Genome Announcements 2013, 1:6. 
28. Klumpp J, Calendar R, Loessner MJ: Complete nucleotide sequence and molecular characterization of bacillus phage TP21 and its relatedness to other phages with the same name. Viruses 2010, 2(4):961-971.

29. Schuch R, Fischetti VA: Detailed genomic analysis of the Wbeta and gamma phages infecting Bacillus anthracis: implications for evolution of environmental fitness and antibiotic resistance. J Bacterio/ 2006, 188(8):3037-3051.

30. Fouts DE, Rasko DA, Cer RZ, Jiang L, Fedorova NB, Shvartsbeyn A, Vamathevan JJ, Tallon L, Althoff R, Arbogast TS, Fadrosh DW, Read TD, Gill SR: Sequencing Bacillus anthracis typing phages gamma and cherry reveals a common ancestry. J Bacteriol 2006, 188(9):3402-3408.

31. Yates MD, Collins $\mathrm{CH}$ : Identification of tubercle bacilli. Annales de Microbiologie 1979, 130B(1):13-19.

32. Yuan Y, Gao M, Wu D, Liu P, Wu Y: Genome characteristics of a novel phage from Bacillus thuringiensis showing high similarity with phage from Bacillus cereus. PLoS One 2012, 7(5):e37557.

33. Swanson MM, Reavy B, Makarova KS, Cock PJ, Hopkins DW, Torrance L, Koonin EV, Taliansky M: Novel bacteriophages containing a genome of another bacteriophage within their genomes. PLoS One 2012, 7(7):e40683.

34. Smeesters PR, Drèze PA, Bousbata S, Parikka KJ, Timmery S, Hu X, Perez-Morga D, Deghorain M, Toussaint A, Mahillon J, Van Melderen L: Characterization of a novel temperate phage originating from a cereulide-producing Bacillus cereus strain. Res Microbiol 2011, 162(4):446-459.

35. Matthew SP, Decker SL, Chamakura KR, Kuty Everett GF: Complete Genome of Bacillus pumilus Siphophage Glittering. Genome Announcements 2013, 1:6.

36. Still EL, Riggi CF, Chamakura KR, Kuty Everett GF: Complete Genome of Bacillus pumilus Siphophage Riggi. Genome Announcements 2013, 1:6.

37. Mash SJ, Minahan NT, Chamakura KR, Kuty Everett GF: Complete Genome of Bacillus pumilus Siphophage Blastoid. Genome Announcements 2013, 1:6.

38. Hastings WJ, Ritter MA, Chamakura KR, Kuty Everett GF: Complete Genome of Bacillus megaterium Siphophage Staley. Genome Announcements 2013, 1:6

39. Decrescenzo AJ, Ritter MA, Chamakura KR, Kuty Everett GF: Complete Genome of Bacillus megaterium Siphophage Slash. Genome Announcements 2013, 1:6.

40. Grose JH, Jensen JD, Merrill BD, Fisher JN, Burnett SH, Breakwell DP: Genome Sequences of Three Novel Bacillus cereus Bacteriophages. Genome Announcements 2014, 2:1

41. Kropinski AM, Hayward M, Agnew MD, Jarrell KF: The genome of BCJA1c: a bacteriophage active against the alkaliphilic bacterium, Bacillus clarkii. Extremophiles 2005, 9(2):99-109.

42. Ritz MP, Perl AL, Colquhoun JM, Chamakura KR, Kuty Everett GF: Complete Genome of Bacillus subtilis Myophage CampHawk. Genome Announcements 2013, 1:6.

43. Bott K, Strauss B: The Carrier State of Bacillus Subtilis Infected with the Transducing Bacteriophage Sp10. Virology 1965, 25:212-225.

44. Lee $J H$, Shin $H$, Son B, Ryu S: Complete genome sequence of Bacillus cereus bacteriophage BCP78. J Virol 2012, 86(1):637-638,

45. Barylski J, Nowicki G, Gozdzicka-Jozefiak A: The discovery of phiAGATE, a novel phage infecting bacillus pumilus, leads to New insights into the phylogeny of the subfamily spounavirinae. PLoS One 2014, 9(1):e86632.

46. Maroun JW, Whitcher KJ, Chamakura KR, Kuty Everett GF: Complete Genome of Bacillus thuringiensis Myophage Spock. Genome Announcements 2013, 1:6.

47. Ting JH, Smyth TB, Chamakura KR, Kuty Everett GF: Complete Genome of Bacillus thuringiensis Myophage BigBertha. Genome Announcements 2013, 1:6.

48. Son B, Yun J, Lim JA, Shin H, Heu S, Ryu S: Characterization of LysB4, an endolysin from the Bacillus cereus-infecting bacteriophage B4. BMC Microbiol 2012, 12:33.

49. Kimura K, Itoh Y: Characterization of poly-gamma-glutamate hydrolase encoded by a bacteriophage genome: possible role in phage infection of Bacillus subtilis encapsulated with poly-gamma-glutamate. Appl Environ Microbiol 2003, 69(5):2491-2497.

50. Loessner MJ, Maier SK, Daubek-Puza H, Wendlinger G, Scherer S: Three Bacillus cereus bacteriophage endolysins are unrelated but reveal high homology to cell wall hydrolases from different bacilli. J Bacteriol 1997, 179(9):2845-2851.

51. Park J, Yun J, Lim JA, Kang DH, Ryu S: Characterization of an endolysin, LysBPS13, from a Bacillus cereus bacteriophage. FEMS Microbiol Lett 2012, 332(1):76-83.

52. Shin H, Lee JH, Park J, Heu S, Ryu S: Characterization and genome analysis of the Bacillus cereus-infecting bacteriophages BPS10C and BPS13. Arch Virol 2014.
53. Boice LB: Evidence that Bacillus subtilis bacteriophage SPO2 is temperate and heteroimmune to bacteriophage phi-105. J Virol 1969, 4(1):47-49.

54. Kong M, Kim M, Ryu S: Complete genome sequence of Bacillus cereus bacteriophage PBC1. J Virol 2012, 86(11):6379-6380.

55. Riva S, Polsinelli M: Relationship between competence for transfection and for transformation. J Virol 1968, 2(6):587-593.

56. Umene K, Shiraishi A: Complete nucleotide sequence of Bacillus subtilis (natto) bacteriophage PM1, a phage associated with disruption of food production. Virus Genes 2013, 46(3):524-534

57. Salvetti S, Faegri K, Ghelardi E, Kolsto AB, Senesi S: Global gene expression profile for swarming Bacillus cereus bacteria. Appl Environ Microbiol 2011, 77(15):5149-5156

58. Gage LP, Fujita DJ: Effect of nalidixic acid on deoxyribonucleic acid synthesis in bacteriophage SPO1-infected Bacillus subtilis.

J Bacteriol 1969, 98(1):96-103.

59. Ganz HH, Law C, Schmuki M, Eichenseher F, Calendar R, Loessner MJ, Getz WM, Korlach J, Beyer W, Klumpp J: Novel giant siphovirus from bacillus anthracis features unusual genome characteristics. PLoS One 2014, 9(1):e85972.

60. Serwer P, Hayes SJ, Thomas JA, Hardies SC: Propagating the missing bacteriophages: a large bacteriophage in a new class. Virol J 2007, 4:21.

61. Krumsiek J, Arnold R, Rattei T: Gepard: a rapid and sensitive tool for creating dotplots on genome scale. Bioinformatics 2007, 23(8):1026-1028.

62. Cresawn SG, Bogel M, Day N, Jacobs-Sera D, Hendrix RW, Hatfull GF: Phamerator: a bioinformatic tool for comparative bacteriophage genomics. BMC Bioinformatics 2011, 12:395.

63. Mahadevan P, King JF, Seto D: Data mining pathogen genomes using GeneOrder and CoreGenes and CGUG: gene order, synteny and in silico proteomes. Int J Comput Biol Drug Des 2009, 2(1):100-114.

64. Turner D, Reynolds D, Seto D, Mahadevan P: CoreGenes3.5: a webserver for the determination of core genes from sets of viral and small bacterial genomes. BMC Res Notes 2013, 6:140.

65. Pope WH, Anders KR, Baird M, Bowman CA, Boyle MM, Broussard GW, Chow T, Clase KL, Cooper S, Cornely KA, DeJong RJ, Delesalle VA, Deng L, Dunbar D, Edgington NP, Ferreira CM, Weston Hafer K, Hartzog GA, Hatherill JR, Hughes LE, Ipapo K, Krukonis GP, Meier CG, Monti DL, Olm MR, Page ST, Peebles CL, Rinehart CA, Rubin MR, Russell DA, et al:: Cluster M mycobacteriophages bongo, PegLeg, and Rey with unusually large repertoires of tRNA isotypes. J Virol 2014, 88(5):2461-2480.

66. Smith KC, Castro-Nallar E, Fisher JN, Breakwell DP, Grose JH, Burnett SH: Phage cluster relationships identified through single gene analysis. BMC Genomics 2013, 14:410.

67. Casjens S, Hendrix R: Control mechanisms in dsDNA bacteriophage assembly. In The Bacteriophages. Edited by Calendar R. New York City: Plenum Press; 1988:15-91. vol. 1.

68. Casjens SR, Thuman-Commike PA: Evolution of mosaically related tailed bacteriophage genomes seen through the lens of phage $\mathrm{P} 22$ virion assembly. Virology 2011, 411(2):393-415

69. Edgar RC: MUSCLE: multiple sequence alignment with high accuracy and high throughput. Nucleic Acids Res 2004, 32(5):1792-1797.

70. Tamura K, Peterson D, Peterson N, Stecher G, Nei M, Kumar S: MEGA5: molecular evolutionary genetics analysis using maximum likelihood, evolutionary distance, and maximum parsimony methods. Mol Biol Evol 2011, 28(10):2731-2739.

71. Casjens SR, Gilcrease EB: Determining DNA packaging strategy by analysis of the termini of the chromosomes in tailed-bacteriophage virions. Methods Mol Biol 2009, 502:91-111.

72. Merrill BD, Grose JH, Breakwell DP, Burnett SH: Characterization of Paenibacillus larvae bacteriophages and their genomic relationships to Firmicute bacteriophages. BMC Genomics 2014, 15:745.

73. Klumpp J, Dorscht J, Lurz R, Bielmann R, Wieland M, Zimmer M, Calendar R, Loessner MJ: The terminally redundant, nonpermuted genome of Listeria bacteriophage A511: a model for the SPO1-like myoviruses of gram-positive bacteria. J Bacterio/ 2008, 190(17):5753-5765.

74. Klumpp J, Lavigne R, Loessner MJ, Ackermann HW: The SPO1-related bacteriophages. Arch Virol 2010, 155(10):1547-1561.

75. Sakaguchi Y, Hayashi T, Kurokawa K, Nakayama K, Oshima K, Fujinaga Y, Ohnishi M, Ohtsubo E, Hattori M, Oguma K: The genome sequence of Clostridium botulinum type $C$ neurotoxin-converting phage and the molecular mechanisms of unstable lysogeny. Proc Natl Acad Sci U S A 2005, 102(48):17472-17477. 
76. Yee LM, Matsumoto T, Yano K, Matsuoka S, Sadaie Y, Yoshikawa H, Asai K: The genome of Bacillus subtilis phage SP10: a comparative analysis with phage SPO1. Biosci Biotechnol Biochem 2011, 75(5):944-952.

77. Dwivedi B, Xue B, Lundin D, Edwards RA, Breitbart M: A bioinformatic analysis of ribonucleotide reductase genes in phage genomes and metagenomes. BMC Evol Biol 2013, 13:33.

78. Parent KN, Gilcrease EB, Casjens SR, Baker TS: Structural evolution of the P22-like phages: comparison of Sf6 and P22 procapsid and virion architectures. Virology 2012, 427(2):177-188.

79. Rizzo AA, Suhanovsky MM, Baker ML, Fraser LC, Jones LM, Rempel DL, Gross ML, Chiu W, Alexandrescu AT, Teschke CM: Multiple functional roles of the accessory I-domain of bacteriophage P22 coat protein revealed by NMR structure and CryoEM modeling. Structure 2014.

80. Shen PS, Domek MJ, Sanz-García E, Makaju A, Taylor RM, Hoggan R, Culumber MD, Oberg CJ, Breakwell DP, Prince JT, Belnap DM: Sequence and structural characterization of great salt lake bacteriophage CW02, a member of the T7-like supergroup. J Virol 2012, 86(15):7907-7917.

81. Poncet S, Milohanic E, Mazé A, Nait Abdallah J, Aké F, Larribe M, Deghmane AE, Taha MK, Dozot M, De Bolle X, Letesson JJ, Deutscher J: Correlations between carbon metabolism and virulence in bacteria. Contrib Microbiol 2009, 16:88-102.

82. Tormo-Mas MA, Donderis J, Garcia-Caballer M, Alt A, Mir-Sanchis I, Marina A, Penades JR: Phage dUTPases control transfer of virulence genes by a proto-oncogenic G protein-like mechanism. Mol Cell 2013, 49(5):947-958.

83. Tormo-Mas MA, Mir I, Shrestha A, Tallent SM, Campoy S, Lasa I, Barbe J, Novick RP, Christie GE, Penades JR: Moonlighting bacteriophage proteins derepress staphylococcal pathogenicity islands. Nature 2010, 465(7299):779-782

84. Koonin EV, Rudd KE: Two domains of superfamily I helicases may exist as separate proteins. Protein Sci 1996, 5(1):178-180.

85. Kim SK, Makino K, Amemura M, Shinagawa H, Nakata A: Molecular analysis of the phoH gene, belonging to the phosphate regulon in Escherichia coli. J Bacterio/ 1993, 175(5):1316-1324.

86. Goldsmith DB, Crosti G, Dwivedi B, McDaniel LD, Varsani A, Suttle CA, Weinbauer MG, Sandaa RA, Breitbart M: Development of phoH as a novel signature gene for assessing marine phage diversity. Appl Environ Microbiol 2011, 77(21):7730-7739.

87. Orth D, Grif K, Dierich MP, Wurzner R: Variability in tellurite resistance and the ter gene cluster among Shiga toxin-producing Escherichia coli isolated from humans, animals and food. Res Microbiol 2007, 158(2):105-111.

88. Maughan $\mathrm{H}$, Van der Auwera $\mathrm{G}$ : Bacillus taxonomy in the genomic era finds phenotypes to be essential though often misleading. Infect Genet Evol 2011, 11(5):789-797.

89. Pilo P, Frey J: Bacillus anthracis: molecular taxonomy, population genetics, phylogeny and patho-evolution. Infect Genet Evol 2011 11(6):1218-1224

90. El-Arabi TF, Griffiths MW, She YM, Villegas A, Lingohr EJ, Kropinski AM: Genome sequence and analysis of a broad-host range lytic bacteriophage that infects the Bacillus cereus group. Virol J 2013, 10:48.

91. Altschul SF, Gish W, Miller W, Myers EW, Lipman DJ: Basic local alignment search tool. J Mol Biol 1990, 215(3):403-410.

92. Lassmann T, Sonnhammer EL: Kalign-an accurate and fast multiple sequence alignment algorithm. BMC Bioinformatics 2005, 6:298

\section{Submit your next manuscript to BioMed Central and take full advantage of:}

- Convenient online submission

- Thorough peer review

- No space constraints or color figure charges

- Immediate publication on acceptance

- Inclusion in PubMed, CAS, Scopus and Google Scholar

- Research which is freely available for redistribution

Submit your manuscript at www.biomedcentral.com/submit
C) Biomed Central 